\title{
A. Interphase Analysis and Control in Fiber Reinforced Thermoplastic Composites
}

\author{
Principal Investigator: Jon J. Kellar \\ Department of Materials and Metallurgical Engineering \\ South Dakota School of Mines and Technology \\ 501 E. St. Joseph Street \\ Rapid City, SD 57701-3901 \\ 605-394-2343, 605-394-3369, jon.kellar@sdsmt.edu
}

Technology Area Development Manager: Joseph A. Carpenter

(202) 586-1022; fax: (202) 586-1600; e-mail: joseph.carpenter@ee.doe.gov

Contractor: South Dakota School of Mines and Technology

Contract No.: DE-FG02-04ER46117

\section{OBJECTIVES}

- Develop the science underlying the formation and effects of transcrystalline regions in carbon fiber reinforced thermoplastic matrix composite systems.

- Exploit the understanding developed from the research described above to allow controlled tailoring of the interphase transcrystallinity for specific applications.

- Analyze processing parameters in new thermoplastic matrix composite technologies, specifically the DRIFT (Direct Reinforcement Fabrication Technology, Southern Research Institute/University of Alabama-Birmingham) and the P4 (Programmable Powered Preform Process, Department of Energy (DOE)/Oak Ridge National Laboratories (ORNL)) processes.

- Generate composites with tailored interphases for specific applications of laminates produced by the DRIFT and P4 processes in the FreedomCAR and other DOE initiatives in lighter weight vehicles.

\section{APPROACH}

- Choose matrix materials relevant to the FreedomCAR and DOE automotive lightweight materials initiatives.

- Characterize the chosen matrix materials with respect to mechanical properties and crystallinity.

- Determine the thermodynamic and practical adhesion between the chosen matrix materials and carbon fibers. The carbon fibers will be both sized and unsized.

- Identify and control the presence and size of transcrystalline regions in the matrix material adjacent the carbon fibers.

- Manufacture laminates using the DRIFT and P4 processes having controlled transcrystalline regions.

- Perform mechanical testing, including tensile testing, impact testing and indentation testing of the laminates having controlled interphases. 


\section{RESEARCH ACCOMPLISHMENTS (SUMMARY)}

\section{Year 1}

- Demonstrated transcrystalline layer formation for Kevlar and pitch-based carbon fibers and polypropylene matrix.

- Measured matrix crystallinity by differential scanning calorimetry

- Designed an apparatus to allow for controlled, resistive, carbon fiber heating for thermodynamic adhesion and transcrystallinity experiments.

- Two students traveled to University of Alabama-Birmingham to meet with Dr. George Husman and view the DRIFT system in place at that university and to obtain DRIFT samples

\section{Year 2}

- Calibrated carbon fiber resistive heating unit for PAN- and pitch-based fibers.

- Measured the maximum shear stress, debond load and friction coefficient for pitch-based carbon fibers having different transcrystalline layer thicknesses. Thicker transcrystalline layers increased all three quantities by $25-50 \%$.

- Measured the transcrystalline layer thicknesses at 2, 7, 15 and $50^{\circ} \mathrm{C} /$ minute cooling rates and determined the variability $(\sim 20 \%)$ of the transcrystalline layer thickness.

- Developed analytical model for determining carbon fiber temperature during resistive heating.

- Measured the tensile properties, including Young's modulus, Poisson's ratio and yield strength of neat polypropylene.

- Developed a sample preparation procedure for examining the transcrystalline interphase regions of thermoplastic polymer beads melted onto carbon fibers.

- Began design and fabrication of a tabletop mini-DRIFT system.

- Principal investigator Dr. Kellar and co-PI Dr. Kjerengtroen visited ORNL to discuss this project.

\section{Year 3}

- Finalized design and build of a compact, laboratory-scale DRIFT machine.

- Completed an operator's manual for the DRIFT machine.

- Conducted preliminary testing with the DRIFT machine for the following fiber/matrix systems: E-glass/polypropylene (PP), Kevlar/nylon, pitch/PP, PAN/PP

- Batch samples (pitch/PP, PAN/PP) for detailed analysis were produced.

- The variable for measured of DRIFT samples was the fiber (pitch or PAN) pre-heat temperature below and within parameters prescribed by the originators of the DRIFT process. The preheat temperatures were room temperature, $225^{\circ} \mathrm{C}$, and $300^{\circ} \mathrm{C}$.

- Samples produced were in the form of continuously reinforced tapes, and were tensile tested and the properties of the sample sets examined.

- Samples were examined using optical and scanning electron microscopy (SEM).

- SDSM\&T research team held two Access Grid meetings with Mr. Robert Norris from ORNL. 


\section{On-Going Collaboration}

- DRIFT samples are being produced for ORNL (Mr. Robert Norris) to evaluate with the P4 process.

\section{RESEARCH ACCOMPLISHMENTS (EXTENDED)}

\section{Year 1}

Research accomplishments during Year 1 occurred in three primary areas: adhesion, mechanical property determination, and extent of crystallinity as a function of formation conditions.

\section{Adhesion}

In Year 1, thermodynamic and practical adhesion research was focused on designing, manufacturing and calibrating several new testing systems and instrumentation. A microbond test system was calibrated for both thermodynamic and practical adhesion. The microbond test system utilized the high precision force measurements afforded by a dynamic mechanical analyzer and precise determination of all the geometric factors associated with microbond testing to achieve the maximum consistency in the microbond test results. This consistency is shown in Table 1 in which the new test system decreased the coefficient of variation by $54 \%$ over the best results our research group had previously achieved. With respect to microbond testing by other groups a similar decrease is observed as typical coefficients of variation are in the $10-20 \%$ range.

Table 1: Comparison of microbond test data.

\begin{tabular}{|c|c|c|}
\hline Test Data & $\begin{array}{c}\text { Average COV/ } \\
\text { Average ci (\%) }\end{array}$ & $\begin{array}{c}\text { Improvement in Data Scatter } \\
\text { COV/ci ratios }\end{array}$ \\
\hline 2001 data & $45.7 / 18.6$ & $5.0 / 4.8$ \\
\hline 2002 data & $41.4 / 19.8$ & $4.5 / 5.1$ \\
\hline 2003 data & $19.7 / 8.5$ & $2.2 / 2.2$ \\
\hline Current setup data & $9.1 / 3.9$ & NA \\
\hline
\end{tabular}

In addition, a Nano-XP nanoindenter was purchased during Year 1 and our group worked to develop procedures (after discussions with Dr. Edgar Lara-Curzio of Oak Ridge National Laboratories) for performing microindentation practical adhesion tests. Initial work focused on using glass fiber-polypropylene and carbon fiber-polypropylene composites manufactured by the DRIFT process and obtained from Dr. George Husman of the University of AlabamaBirmingham. The Year 1 work concentrated on identifying the primary issues associated with testing. Of particular importance are obtaining flat surfaces without debonding the fibers from the matrix prior to testing and splitting of the fibers during indentation.

To simulate DRIFT manufacturing of samples for microbond practical adhesion testing and thermodynamic adhesion measurements, a furnace capable of resistively heating carbon fibers was manufactured. Figure 1 shows both an overview and a close-up of the fiber heating assembly of this apparatus. Figure 2 shows the resistance versus temperature of three of the six carbon fibers. The important issue from Figure 2 is that the slope of the resistance-temperature curve is essentially the same for all three fibers. The difference in the lines is due to slight 
differences in the diameter of the carbon fibers. Also, the linearity of the resistance-temperature curve is very high $(>0.995)$ in all cases.

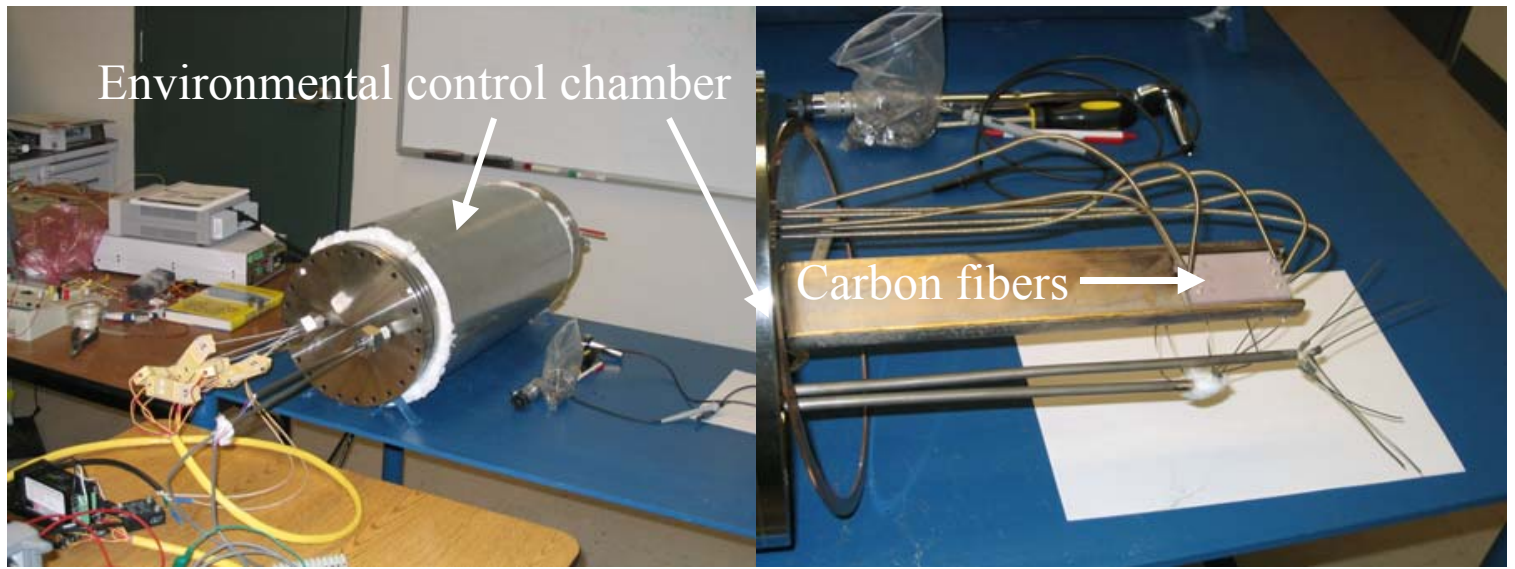

Figure 1. Apparatus for resistively heating carbon fibers. The left photo shows the full apparatus, while the right photo shows a close-up of the fiber heating portion of the apparatus.

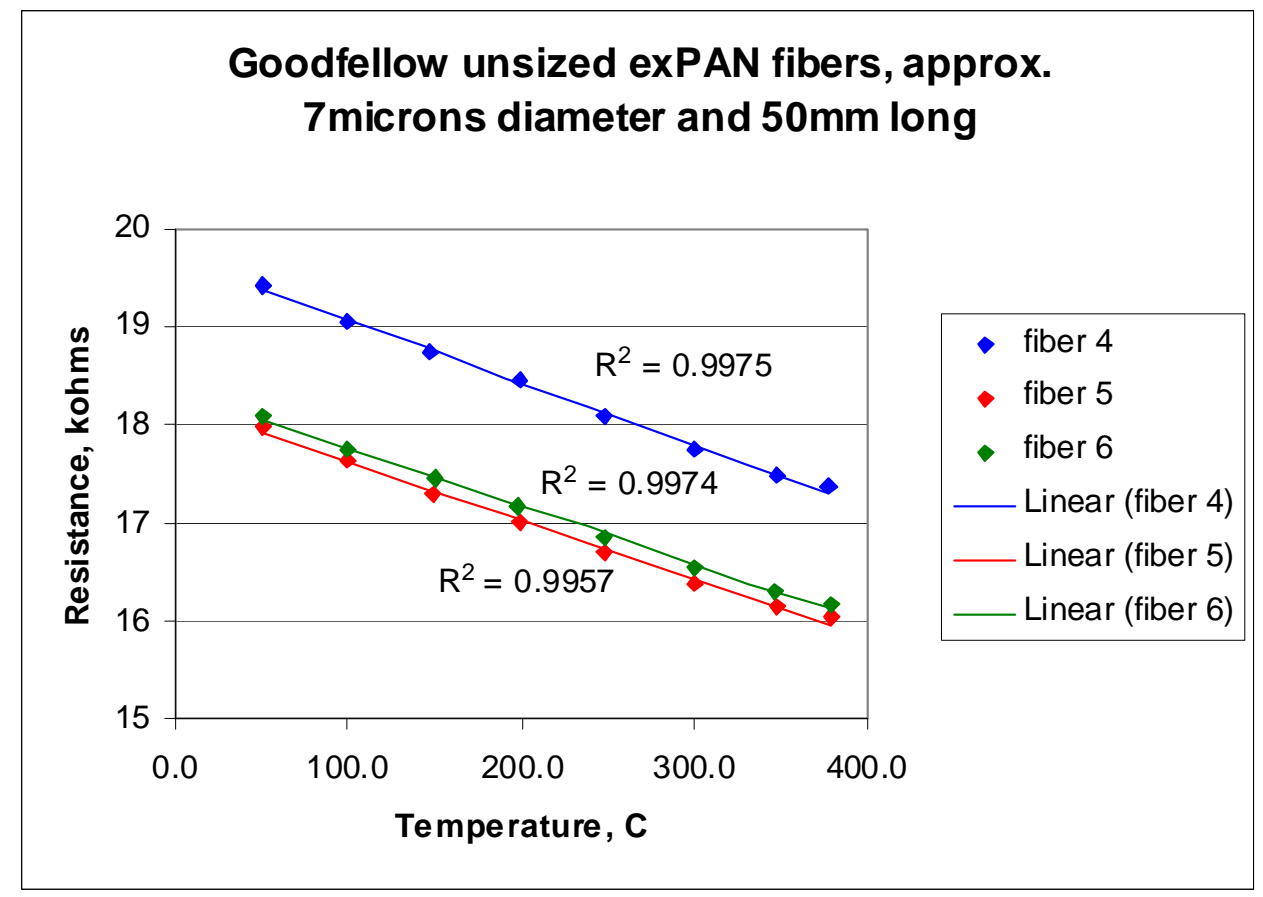

Figure 2. Measured carbon fiber resistance as a function of applied temperature.

Finally, contact angles of polypropylene on carbon fibers has been measured for slow cooling conditions. In the cases studied thus far, polypropylene has exhibited a close to zero contact angle indicating that molten polypropylene wets carbon fibers if given sufficient time.

\section{Mechanical Property Determination}

To manufacture samples for mechanical testing a Wabash heatable-coolable press was used to manufacture blanks from which tensile and dynamic mechanical analysis (DMA) samples could 
be cut. As control of the heating and cooling rates is critical for the success of this work, the first area studied was the profile of the heating and cooling rate at different points on the surface of the press. The heating rate was expected to be reasonably consistent across the platens; but, due to the way platen cooling is done, the cooling rate (which is more important in this work than the heating rate) was expected to be quite variable. As Figure 3 (right) shows, the heating rate was constant across the platen to about $0.2^{\circ} \mathrm{C}$ for a $6{ }^{\circ} \mathrm{C}$ /minute heating rate. For the cooling rate, the left graph in Figure 3 indicates that the cooling rate varies by about $\pm 2{ }^{\circ} \mathrm{C}$ for an $18{ }^{\circ} \mathrm{C} /$ minute cooling rate. Therefore, the cooling arte varies by about a factor of 3 compared to the heating rate. Examination of Figure 3 indicates that the central region of about 6" by 6" has a stable enough cooling rate that mechanical testing samples could be cut from this region and still be considered homogeneous.
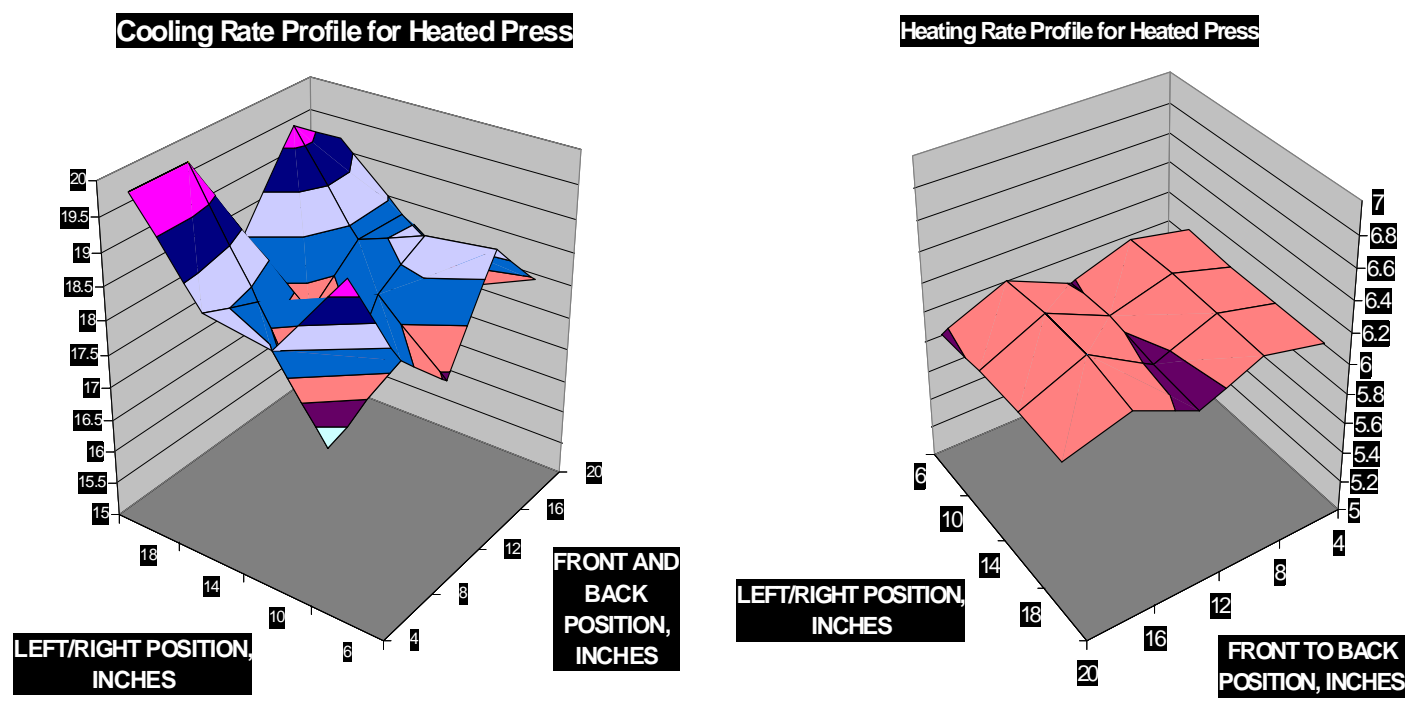

Figure 3. Cooling (left) and heating (right) rate profiles for the Wabash press.

Both tensile testing and DMA samples were manufactured. The tensile testing measured the Young's modulus and yield strength of samples made from glass fiber-polypropylene DRIFT process laminates. Little difference was observed for different cooling rates.

For DMA testing of bulk polypropylene samples, Figures 4 and 5 show the storage and loss moduli (Figure 4) and creep compliance (Figure 5). The storage and loss moduli were relatively constant as a function of cooling rate between about 5 and $20^{\circ} \mathrm{C} /$ minute. As the crystallinity of the matrix is greater at slower cooling rates compared to faster cooling rates, this indicates that the matrix crystallinity has little effect when a sinusoidal load is applied at $1 \mathrm{~Hz}$ with an amplitude of 15 micrometers. Conversely, the creep compliance is a function of the cooling rate and hence the matrix crystallinity. The creep compliance is approximately twice as great when the cooling rate was $\sim 7.5^{\circ} \mathrm{C} /$ minute as compared to when the cooling rate was $\sim 21{ }^{\circ} \mathrm{C} /$ minute. 


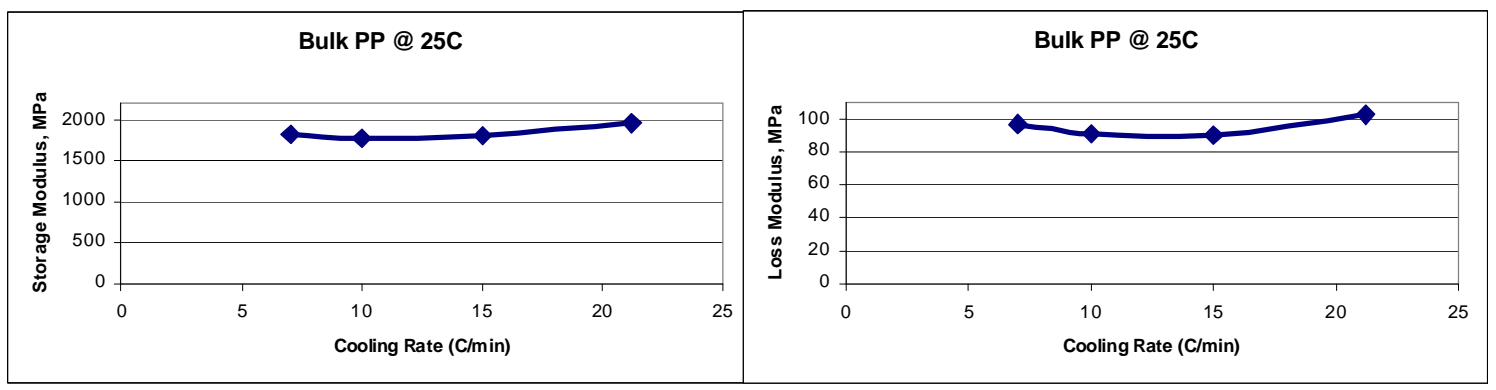

Figure 4. Storage modulus (left) and Loss modulus (right) of bulk polypropylene as a function of cooling rate.

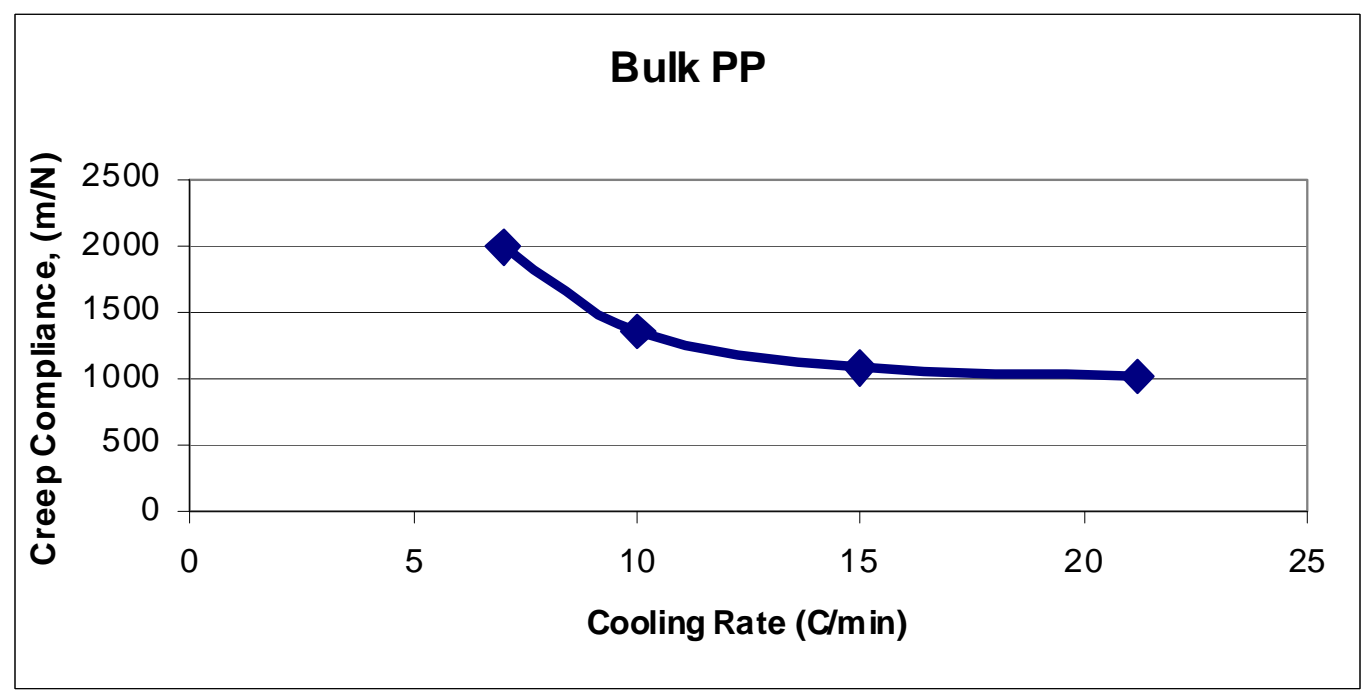

Figure 5. Creep compliance of bulk polypropylene as a function of cooling rate.

\section{Extent of Crystallinity as a Function of Formation Conditions}

Crystallinity formation was studied by two types of experimentation. In one type of experiment, bulk polypropylene samples were placed in a differential scanning calorimeter (DSC) and the crystallization exotherm/endotherm was used to determine the amount of crystallization by either isothermal crystallization (exotherm) or nonisothermal crystallization(endotherm). Figure 6 shows the results from these two types of experimentation. Isothermal crystallization, Figure 6 (left), shows little difference in the crystallization as a function of hold time at the isothermal crystallization temperature $\left(115^{\circ} \mathrm{C}\right)$. This is because essentially all the crystallization occurs in the first two minutes. For nonisothermal crystallization, Figure 6 (right), the cooling rate is varied then the amount of crystallization is determined from the endothermic crystallization melting during the next heating cycle. The amount of bulk crystallization is quite dependent upon the cooling rate, for cooling rates less than $10^{\circ} \mathrm{C} /$ minute. Nonisothermal crystallization typically is a better representation of the cooling during DRIFT and P4 processing. 


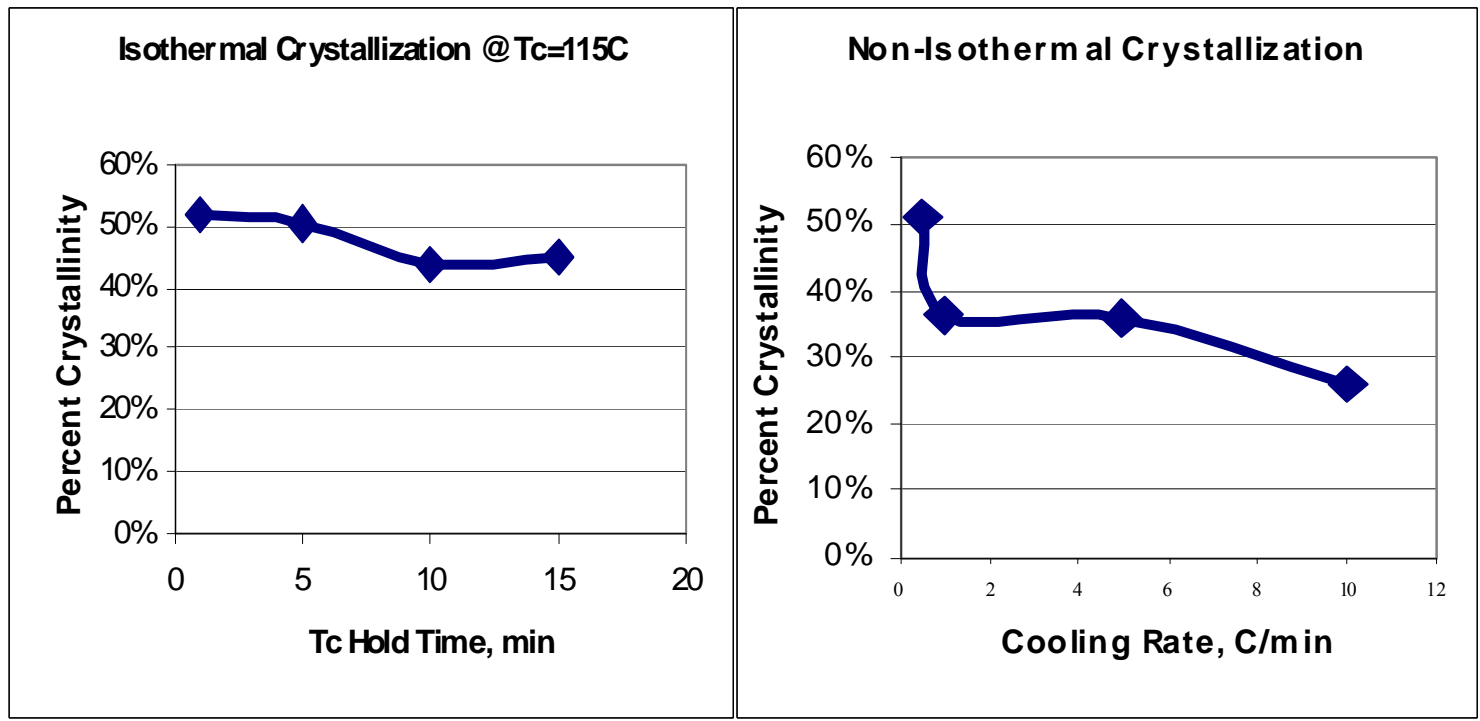

Figure 6. Isothermal (left) and nonisothermal (right) determination of bulk polypropylene crystallization.

In addition to bulk testing, experiments were conducted to examine transcrystalline layer formation during cooling. These experiments used a hot stage mounted on a polarized microscope stage. Two thin layers of polypropylene with a small number of fibers sandwiched between the layers were placed in the hot stage and heated to approximately $200^{\circ} \mathrm{C}$ for 10 minutes. After this hold well above the polypropylene melting temperature, the stage was slowly cooled and the crystallization recorded with a video camera mounted to the polarized microscope. Figures 7 and 8 show transcrystalline layer formation for pitch-based, carbon fibers (Figure 7) and Kevlar ${ }^{\circledR}$ fibers (Figure 8). Glass fibers and ex-PAN (polyacrylonitrile) carbon fibers were also tested. The glass fibers used did not show any transcrystallinity, while the exPAN fibers intermittently showed transcrystallinity. The ex-PAN transcrystallinity generally took the form of hemispherical regions growing from the fiber surface rather than the more lamellar regions seen in Figures 7 and 8. This is most likely due to the number of nucleation sites on the ex-PAN fibers being much les than the number of nucleation sites on pitch or Kevlar $^{\circledR}$ fibers.

\section{Year 2}

Research accomplishments during Year 2 occurred in two primary areas: interphase formation conditions, and effect of transcrystallinity on composite performance. Research in each of the two areas is described below.

\section{$\underline{\text { Interphase Formation Conditions }}$}

Interphase formation conditions were investigated in three primary areas: adhesion, mechanical property determination and extent of crystallinity as a function of formation conditions. 


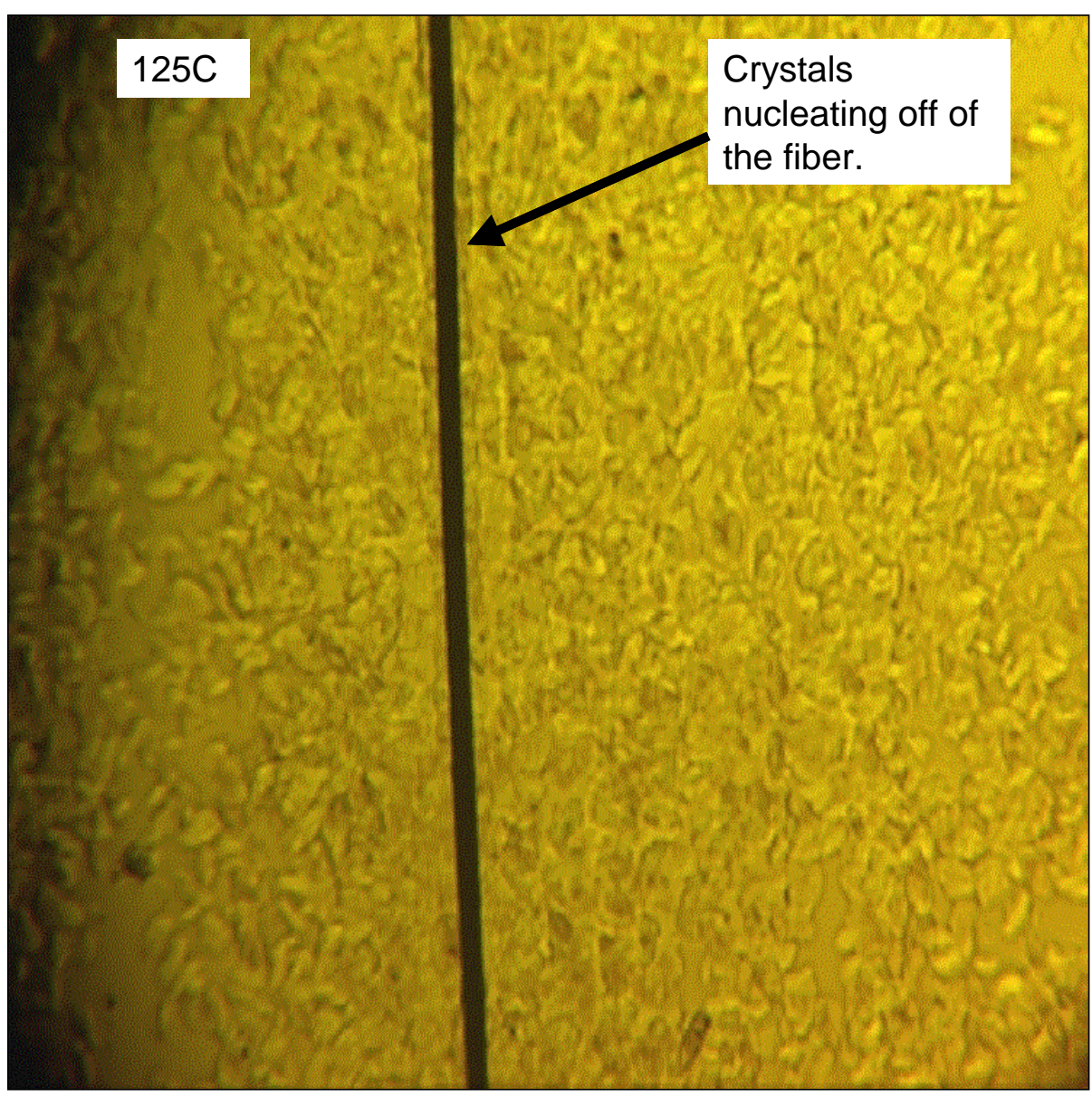

Figure 7. Transcrystalline layer on pitch-based carbon fibers.

\section{Adhesion}

Thermodynamic adhesion research mainly focused on extending the recently developed fiber resistive heating apparatus to the use of pitch-based fibers, while practical adhesion was studied through microindentation testing of model composite systems.

Thermodynamic Adhesion Thermodynamic adhesion, in this work, was primarily concerned with the measurement of the contact angle of polymer beads on fibers of interest. The melting of beads on carbon and subsequent control of cooling rate is necessary for understanding of the effect of transcrystallinity on the thermodynamic adhesion. To manufacture the beads in a manner similar to the DRIFT process, a technique to resistively heat the carbon fibers has been developed. This system was calibrated and a variety of fibers tested to determine the reproducibility of fiber heating and of the resistivity $\left(\right.$ at $\left.20^{\circ} \mathrm{C}\right)$ and temperature coefficient. Figure 9 shows a graph of the data obtained for several PAN-derived, carbon fibers and several pitch-based, carbon fibers. Literature values for carbon are also shown. As shown in Figure 9, the data for the various fiber types exhibit relatively small levels of variation as the coefficients of variation for both the resistivity (at $20^{\circ} \mathrm{C}$ ) and the temperature coefficients are less than $11.5 \%$ for both fiber types. Compared to the literature values, both fiber types exhibit smaller 
magnitude temperature coefficients $(16-19 \mu \mathrm{ohm} * \mathrm{~m}$ for PAN fibers and 13-15 $\mu \mathrm{ohm} * \mathrm{~m}$ for pitch based fibers) and larger resistivity at $20{ }^{\circ} \mathrm{C}\left(-2.5\right.$ to $-3 \times 10^{-4} \mathrm{~K}^{-1}$ for PAN fibers and -1 to -2 $\mathrm{x} 10^{-4} \mathrm{~K}^{-1}$ for pitch-based fibers). The resistivity of carbon given in the literature varies from about 3-60 $\mu \mathrm{ohm} * \mathrm{~m}$ depending upon the crystal structure and the presence of impurities. Only one literature value for the temperature coefficient was found. The importance of this data for this work is that pitch-based, carbon fibers have the smallest temperature coefficient, which will increase the imprecision of determining the fiber temperature during resistive heating from about $2{ }^{\circ} \mathrm{C}$ for PAN-based, carbon fibers to about $7{ }^{\circ} \mathrm{C}$ for pitch-based, carbon fibers.

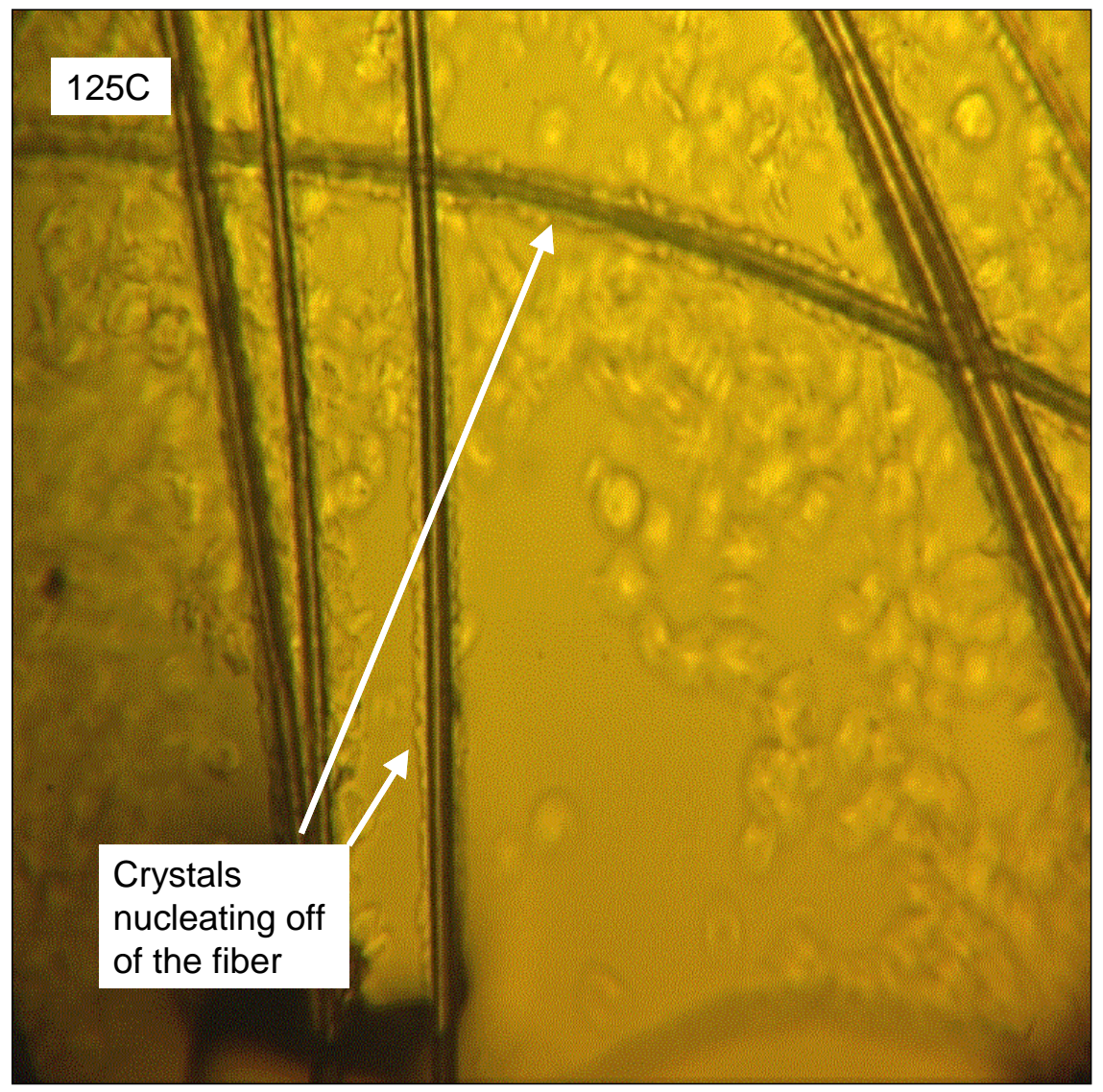

Figure 8. Transcrystalline layer around Kevlar fibers.

Interphase regions are known to significantly affect the mechanical properties, such as strength and impact resistance, in thermoplastic composites. Generally, both the temperature and the rate of change in the temperature, affect the formation of transcrystalline regions during manufacturing processes. Thus, analyzing thermal behaviors of the transcrystalline regions during heating and cooling processes is important in understanding the mechanisms of formation/ growth of the transcrystalline regions. To better understand these thermal behaviors, a model was developed.

A nonlinear differential equation was obtained by applying an energy balance principle on a finite element of the carbon fiber model. The model was then discretized and the corresponding difference equation was coded by Matlab. A negligible temperature gradient along the fiber was 
observed, except at the very end regions, close to the electric poles. Therefore, conduction along the wire could be neglected. Because the time to reach the steady state temperature is less than $200 \mathrm{msec}$, transient temperature effects can also be neglected. In addition, the natural convective heat transfer term can be neglected, because its value is far less than that of the radiation heat transfer term. Thus, the applied electric energy is balanced only by the radiation heat transfer term and can be approximated further into an algebraic steady state temperature equation in terms of the input supply voltage as shown by Equation 1. In Equation 1, $V_{s}$ is the applied voltage, $r$ is the fiber radius and $L$ is the length of the carbon fiber, while $\sigma$ and $\varepsilon$ are the StefanBoltzmann constant and the emissivity, respectively. Finally, $\mathrm{T}$ is the temperature of the fiber and $\mathrm{T}_{\infty}$ is the air temperature.

$$
\frac{2 \sigma \varepsilon\left(T^{4}-T_{\infty}^{4}\right)}{r}+\frac{V_{s}^{2}}{L^{2} \rho_{e}\left[1+\alpha\left(T-T_{\infty}\right)\right]}=0
$$

Equation 1 was solved by a root finding algorithm. This equation shows how the temperature of a carbon fiber $(\mathrm{T})$ to be controlled by adjusting the input electric voltage. However, predicting the temperature is significantly affected by the uncertainty of input parameters such as electric resistivity $\left(\rho_{\mathrm{e}}\right)$ and the temperature coefficient of resistivity $(\alpha)$ of the carbon fiber. The values for these parameters measured in this work are shown in Figure 9. No technique was found to directly measure the surface temperature of the heated carbon fiber; thus, the temperature is approximated by melting thermoplastic polymers with a known melting temperature.

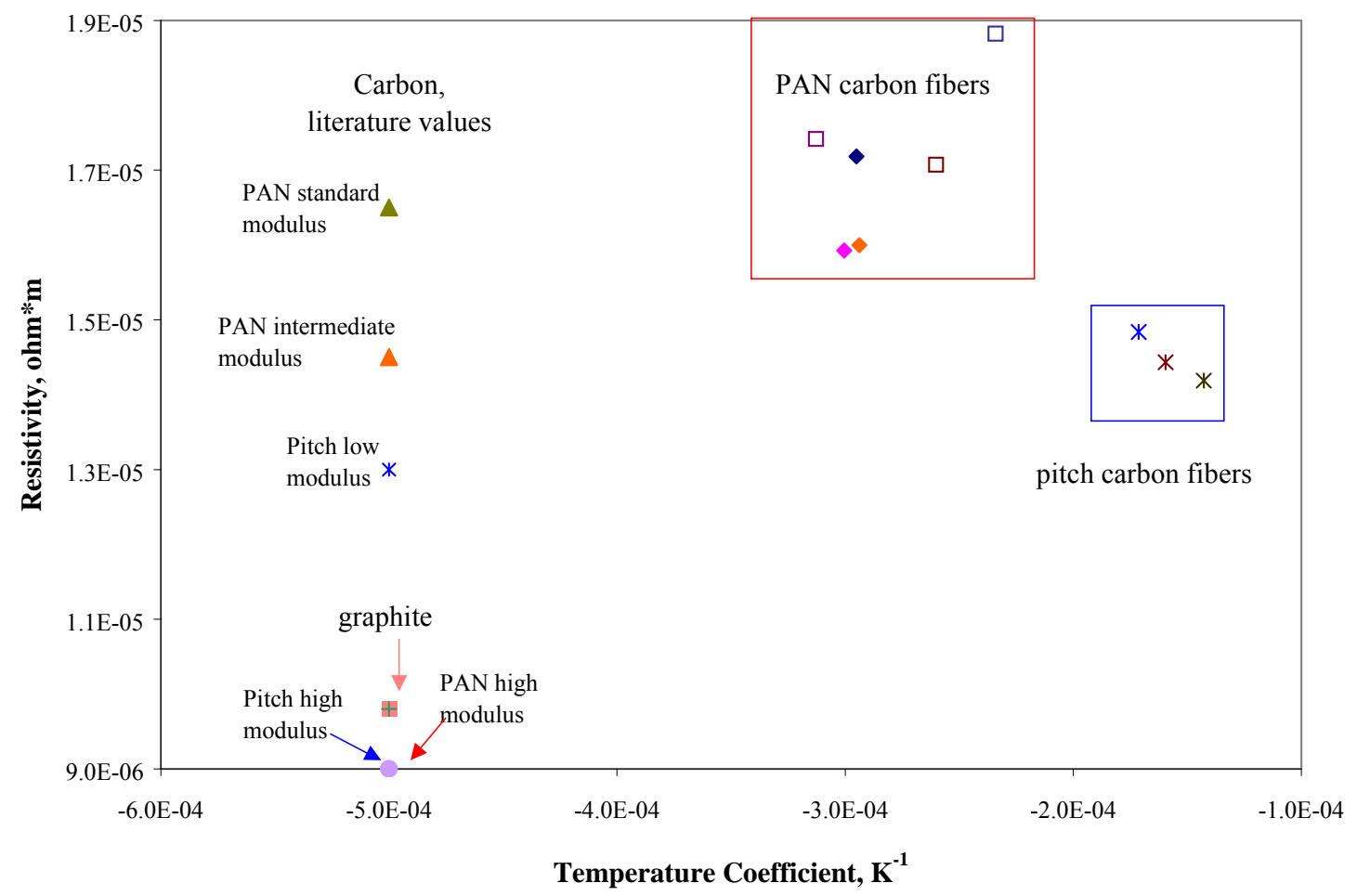

Figure 9. Temperature coefficient and resistvity at $20^{\circ} \mathrm{C}$ determined for the fibers used in this work compared to literature values for various types of carbon. 
Practical Adhesion To measure the practical adhesion, model unidirectional composite samples were manufactured by compression molding a thin, polypropylene/pitch-based carbon fiber laminate at $205^{\circ} \mathrm{C}$ at 0.3 tons pressure for 30 minutes to erase the thermal history of the PP. After the melting hold time, the samples were cooled at $2{ }^{\circ} \mathrm{C} /$ minute using the press cooling ability and at $\sim 50^{\circ} \mathrm{C} /$ minute using dry ice applied to the top and bottom mold surface. As will be shown in the Extent of Crystallinity as a Function of Formation Conditions section, these cooling rates produced different thicknesses of transcrystalline regions around the fibers, about $100 \mu \mathrm{m}$ thick for $2^{\circ} \mathrm{C} /$ minute and $20 \mu \mathrm{m}$ thick for $50^{\circ} \mathrm{C} /$ minute.

These samples were prepared for practical adhesion (microindentation) testing so that the total thickness was about $76 \mu \mathrm{m}$. A thin sample such as this was necessary for push-through microindentation testing. Individual fibers were located and indented using a force ramped from 0 to $60 \mathrm{mN}$ over 30 seconds and held at the maximum value for 10 seconds. Unloading occurred over the same time range as did loading. For the cooling rates examined at least 15 fibers were debonded.

There are typically four different regions of the load-displacement curve. Stage I is the initial loading of the fiber. In this stage, the indenter goes from no contact to full contact with the fiber surface, making this region non-linear since the contacted area of the tip is increasing with the load. Stage II is the linear sample-loading segment. The fiber and matrix are deflecting under load with no relative motion between the two. Stage III is the crack initiation and debonding region of the curve. The initial part is where the mode II crack initiates at the fiber/matrix interface. The crack grows to an unstable state until the entire fiber is completely debonded from the matrix. Stage IV is the region where the fiber is sliding along the interface. The debond load was calculated for each test performed. Also, the maximum shear stress (MSS) was calculated from shear-lag theory and the slope of Stage II. Finally, the post-debonding behavior was modeled using a sliding friction model.

Table 2 contains a comparison of the microindentation data for the two cooling rates. The more rapidly cooled sample, having a larger transcrystalline layer thickness $(100 \mu \mathrm{m}$ vs. $20 \mu \mathrm{m})$, exhibits a greater MSS (37\% greater) and debond load (46.5\% greater). Theses differences are statistically significant at the $90 \%$ level.

Table 2: Microindentation test data

\begin{tabular}{|c|c|c|c|}
\hline & $\begin{array}{c}\text { Maximum Shear } \\
\text { Stress, MPa }\end{array}$ & $\begin{array}{c}\text { Debond Load, } \\
\mathrm{mN}\end{array}$ & $\begin{array}{c}\text { Friction } \\
\text { Coefficient }\end{array}$ \\
\hline $2{ }^{\circ} \mathrm{C} /$ minute & $0.37 \pm 0.13$ & $38.7 \pm 12.5$ & $<0.2$ \\
\hline $50^{\circ} \mathrm{C} /$ minute & $0.27 \pm 0.05$ & $26.4 \pm 5.8$ & $<0.1$ \\
\hline
\end{tabular}

Mechanical Property Determination The tensile properties of pure polypropylene were studied during Year 2. The polypropylene samples were manufactured using a Wabash press with stops to ensure a sample thickness of $2.9 \mathrm{~mm}$. The specimens were heated at $5{ }^{\circ} \mathrm{C} /$ minute to $200{ }^{\circ} \mathrm{C}$ held at this temperature for 10 minutes then cooled at $10^{\circ} \mathrm{C} /$ minute. Following cutting the samples to ASTM D638, Type I sample size specifications, strain gauges were affixed to determine the Poisson's ratio and tensile tests were performed according to ASTM D638 with a rate of $5 \mathrm{~mm} /$ minute leading to specimen failure in approximately 1 minute. Figure 10 shows a 
typical stress-strain curve for these samples. At the strain rate utilized, the Young's modulus shown in Figure 10 is $1950 \mathrm{MPa}$, while the average Young's modulus found was $2130 \pm 350$ $\mathrm{MPa}$. The yield strength was also found from the stress-strain curve and the mean yield strength found was $7.0 \pm 2.3 \mathrm{MPa}$. Finally, the mean Poisson's ratio was determined to be $0.326 \pm 0.018$.

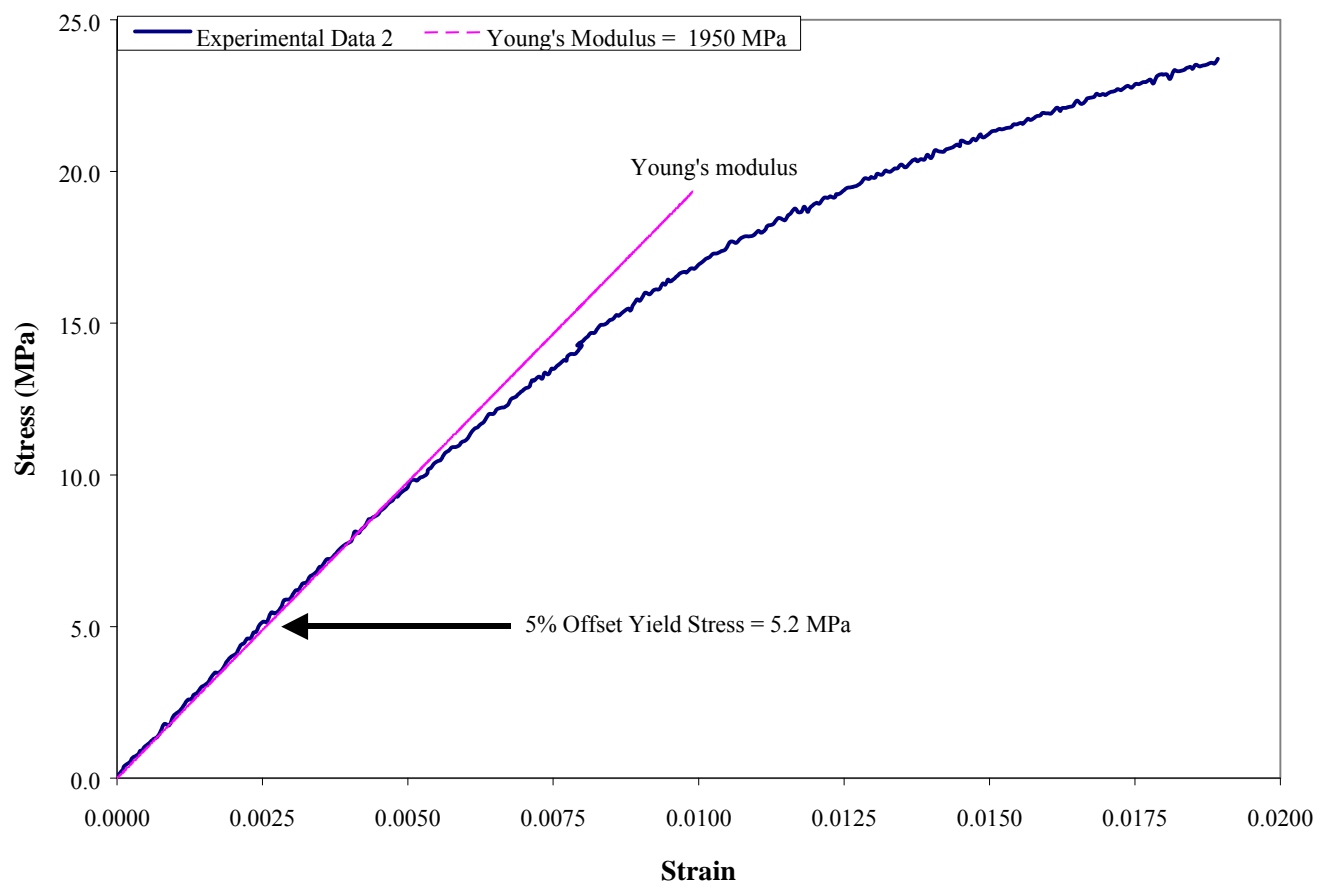

Figure 10. Typical stress-strain cuve of polypropylene tested at $5 \mathrm{~mm} /$ minute.

Also, on certain samples, strain gauges were placed on both the top and bottom of the specimen. Little difference was observed between the two sides of the sample indicating that the top and bottom of the tensile samples were in the same state of tension.

\section{Extent of Crystallinity as a Function of Formation Conditions}

To investigate the extent of crystallinity as a function of formation conditions in greater detail, research efforts were directed towards two areas: 1 . transcrystalline layer formation and 2 . sectioning polypropylene beads on carbon fibers perpendicular to the long fiber axis.

Transcrystalline Layer Formation Experiments were conducted to examine transcrystalline layer formation during cooling. These experiments used a hot stage mounted on a polarized microscope stage. Two thin layers of polypropylene with a small number of fibers sandwiched between the layers were placed in the hot stage and heated to approximately $200{ }^{\circ} \mathrm{C}$ for 10 minutes. After this hold, the stage was slowly cooled at various rates and the crystallization recorded with a video camera mounted to the polarized microscope. Following examination of the transcrystalline layer by video, the samples were microtomed and etched using a potassium permanganate/sulfuricacid/orthophosphoric acid etchant. Figure 11 shows scanning electron microscope micrographs of the etched samples. As seen in Figure 11, the transcrystalline layers 
were quite variable in thickness. This had been observed previously, and was quantified from the video micrographs taken in this research for a $\mathrm{PP} /$ pitch-based carbon fiber system. The mean transcrystalline layer thickness was 3.3 times the fiber diameter $(\sim 10 \mu \mathrm{m})$ or about $30-35 \mu \mathrm{m}$. The standard deviation of measurements is 0.7 times the fiber diameter, giving a coefficient of variation of about $20 \%$. From Figure 11 and similar figures not shown in this report, the thicknesses of the transcrystalline layer were estimated. The slow cooled $\left(2{ }^{\circ} \mathrm{C} /\right.$ minute $)$ samples exhibited a significantly larger transcrystalline layer thickness $(\sim 100 \mu \mathrm{m})$ than the other three cooling rates all of which exhibited approximately $20 \mu \mathrm{m}$ thick transcrystalline layers.

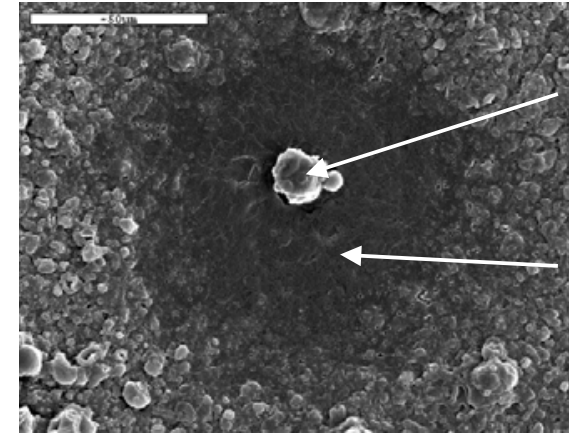

$2{ }^{\circ} \mathrm{C} /$ minute, bar is $50 \mu \mathrm{m}$

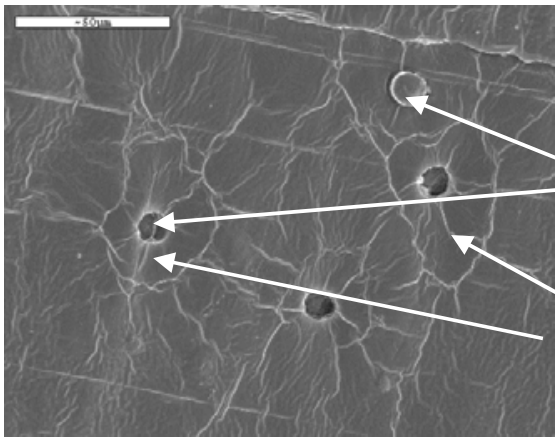

$15^{\circ} \mathrm{C} /$ minute, bar is $50 \mu \mathrm{m}$

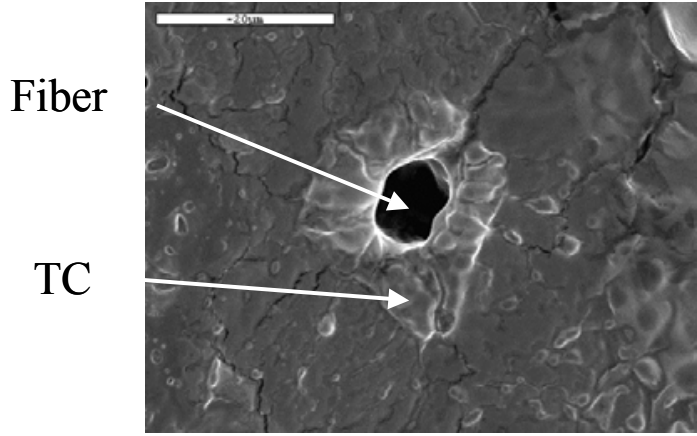

$7^{\circ} \mathrm{C} /$ minute, bar is $20 \mu \mathrm{m}$

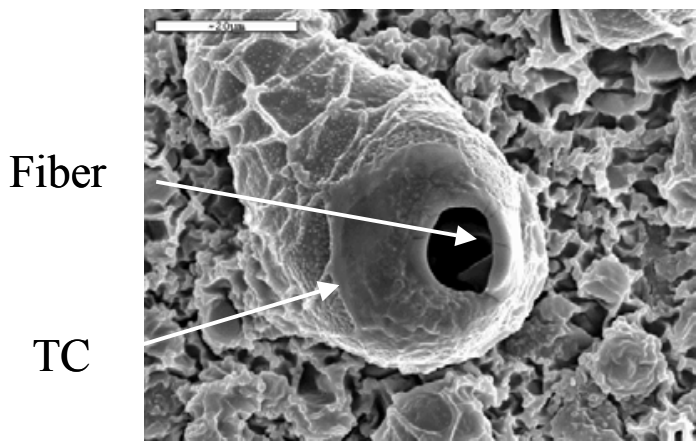

$50^{\circ} \mathrm{C} /$ minute, bar is $20 \mu \mathrm{m}$

Figure 11. Transcrystalline regions developed around pitch-based, carbon fibers at various cooling rates. TC indicates transcrystalline region. In some cases, the fiber regions indicated on the graph are places where fibers had been pulled out of the surface during sample preparation.

Sectioning polypropylene bead

To obtain samples suitable for atomic force microscopic examination of polypropylene beads, sectioning of the bead perpendicular to the fiber long axis was necessary. Bead sectioning was accomplished by embedding the bead and fiber in an epoxy matrix then polishing the resultant cylinder until the bead was reached. Once the bead was found, polishing with $5 \mu \mathrm{m} \mathrm{Al} \mathrm{O}_{3}$ for 2 minutes, then $1 \mu \mathrm{m} \mathrm{Al} \mathrm{O}_{3}$ for 1 minute and $0.3 \mu \mathrm{m} \mathrm{Al}{ }_{2} \mathrm{O}_{3}$ for 1-5 minutes was used to yield a surface suitable for atomic force microscopy (AFM).

AFM interrogation of the region surrounding the carbon fiber is shown in Figure 12. In Figure 12 , a $10.5 \mu \mathrm{m} \times 10.5 \mu \mathrm{m}$ region is shown in both height (left image) and phase (right image). The fiber is clearly observed but no obvious transcrystalline layer was observed in this case as 
the transcrystalline layer is expected to be larger than the area studied. The efficacy of the sample preparation procedure is shown in the less than $500 \mathrm{~nm}$ height difference over the whole of the sample.

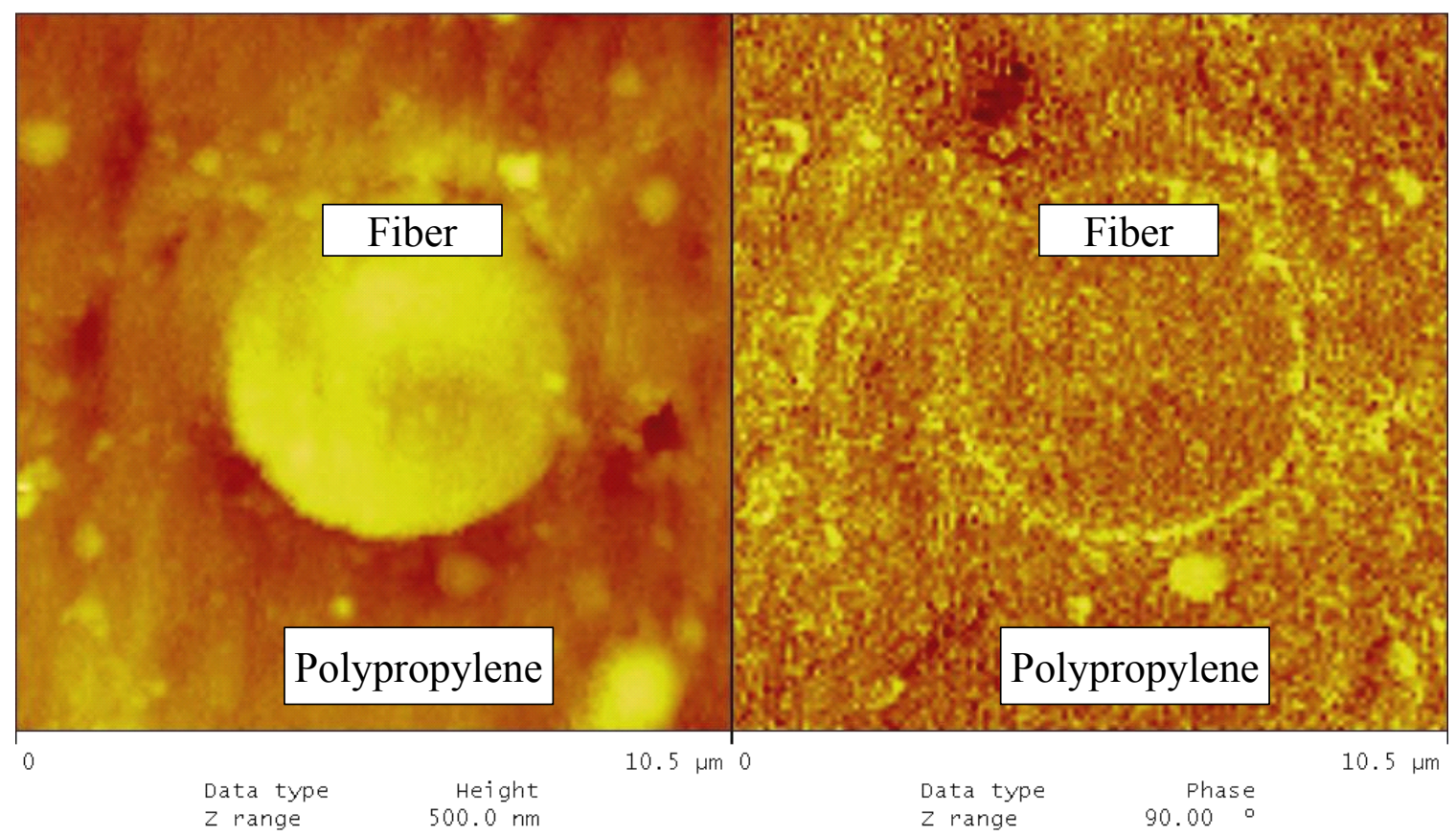

Figure 12. Atomic force micrograph of a polypropylene bead containing a carbon fiber encased in epoxy. The left image is a height image (500 nm maximum height), while the right image is a phase image $\left(90^{\circ}\right.$ maximum phase change).

\section{Year 3}

Research accomplishments during Year 3 occurred primarily in the effect of transcrystallinity on composite performance area; specifically, the manufacture and testing of specimen using a custom designed mini-DRIFT machine. Research in this area is described below.

Research on the effect of transcrystallinity on composite performance centered on developing a miniature DRIFT machine. Initially the research plan involved using an existing DRIFT machine at the University of Alabama-Birmingham (UAB). However, the group at UAB disbanded, and with that there existed a need to fabricate a local DRIFT machine. The goal of this mini-DRIFT research was to develop a system for producing lab-scale thermoplastic composite prepreg samples using the DRIFT process. The DRIFT process is a procedure for making continuous-fiber prepreg materials. In the process a continuous-fiber reinforcement material is drawn through a molten resin after being heated beyond the temperature of the resin. While in the resin, a shear is applied to the reinforcement material leaving substantially no voids in the prepreg material (Patent Number: 5,911,932). One of the goals of this aspect of this research is to control and monitor operating parameters and their effects on fiber wetting and material properties. The parameters to be controlled include: fiber draw speed, fiber tension, fiber preheat temperature, resin temperature, and prepreg cooling. Two primary areas with respect to the mini-DRIFT machine were completed. One area investigated was the manufacture 
of the mini-DRIFT machine and the second area investigated was assessment of the product quality of the mini-DRIFT manufactured composite materials.

\section{Mini-DRIFT Manufacture}

There were three primary goals identified for this phase of the research:

1. Make the DRIFT process less "art" and more "science".

2. Make the machine of smaller scale for research purposes.

3. Allow for system adjustability for experimentation.

These goals resulted in a set of requirements for the mini-DRIFT machine. These requirements were:

1. System variables should be accurately monitored and controlled.

2. Based on available lab space, the machine should have a footprint of approximately 4 feet by 8 feet.

3. Allow for up to $20 \mathrm{~K}$ fiber tows.

4. The machine should have the ability to heat the fibers up to $\sim 450{ }^{\circ} \mathrm{C}$.

5. Allow for system flexibility and adjustment through replaceable die heads, moveable/ replaceable shear pins, and sufficient temperature operating range.

The design and manufacturing of the mini-DRIFT machine culminated early in Year 3 . There were five primary components to the design:

1. Extruder

2. Impregnation Tool/Tool Heating

3. Fiber Puller/Fiber Feed

4. Fiber Heating

5. Chiller

The design process for these components is described in detail the in M.S. thesis of Mr. R.D. McGlothlen. The extruder chosen was one already located at the site where the mini-DRIFT machine would be located. This extruder was a Haake PolyLab extruder as shown in Figure 13. This extruder has a maximum operating temperature of $450{ }^{\circ} \mathrm{C}$ and maximum throughput of 5 $\mathrm{kg} / \mathrm{hr}$. Both of these meet or exceed the requirements for the DRIFT design.

The impregnation tool was designed after visiting an operating DRIFT machine at the University of Alabama-Birmingham and was made to fit the Haake extruder. Figure 14 show the impregnation tool with front face removed. The pins over which the fibers travel are adjustable to accommodate different fiber types. The tool is able to be completely taken apart for cleaning and for use of different fiber entrance and exit plates for tows of differing sizes. In addition, the tool was designed with a cartridge heating system using four heaters with temperature feedback provided by a thermocouple inserted into the center of the tool. This design feature allowed the tool to be kept at the processing temperature of the molten thermoplastic material dispensed into the tool from the extruder. 


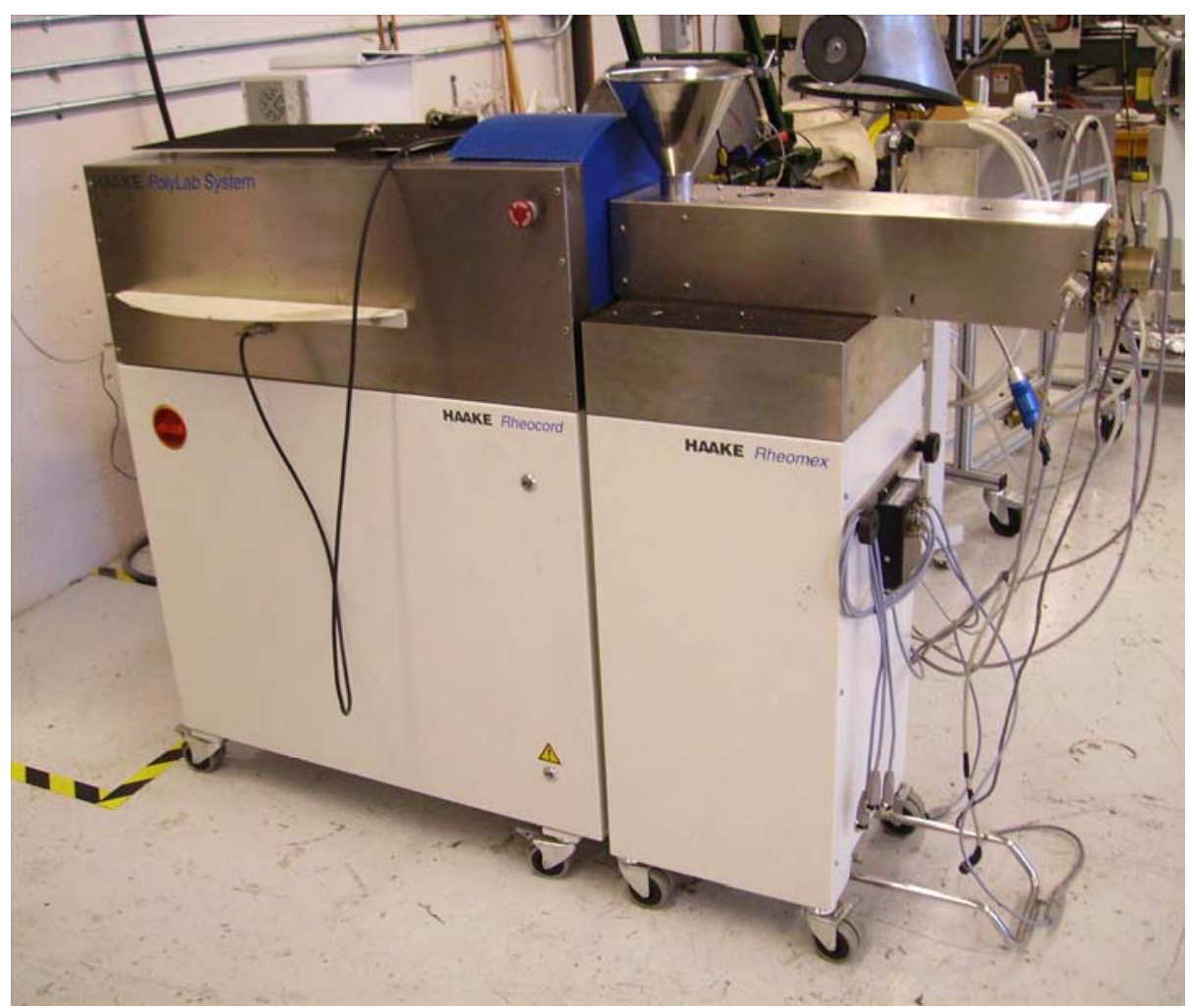

Figure 13. Haake PolyLab extruder.

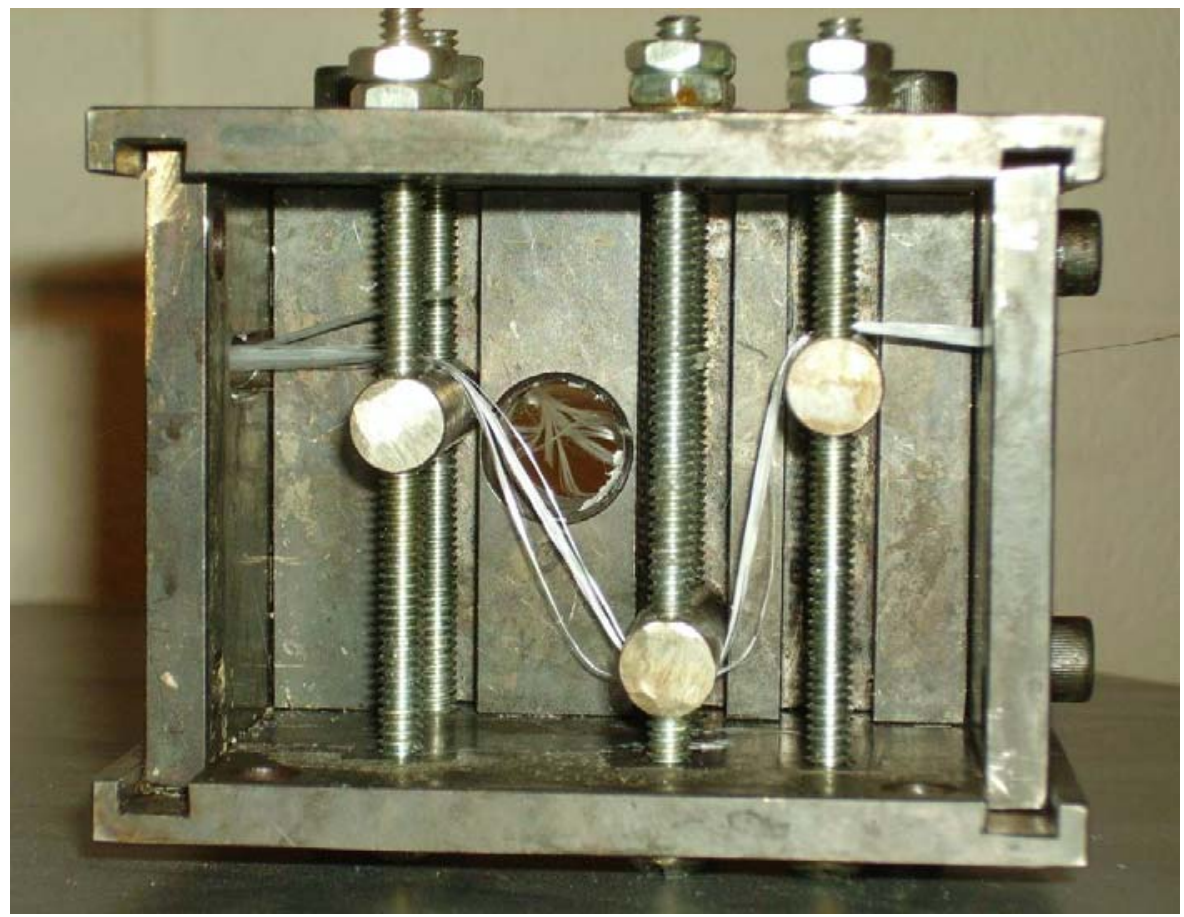

Figure 14. Impregnation tool with side plate removed showing fiber routing.

The third portion of the mini-DRIFT machine is the fiber puller and feed assembly. The fiber puller chosen is shown in Figure 15 and consists mainly of pulling the fibers through two 
motorized, rubber-surfaced drums. The drums have an aluminum core coated in $60 \mathrm{~A}$ durometer polyurethane. The coating provides a firm grip on the material being processed, but prevents the material from being damaged. One drum was fixed in position and the other was attached to an adjustable lever arm to allow for adjustment of the gripping force on the fibers. The stationary wheel was attached to a keyed shaft driven by a motor through a belt and pulley system to reduce the motor speed. The motor was controlled by a Genesis variable-frequency-drive, which allowed accurate control of the motor speed. The frame for the puller was constructed of $2 \mathrm{in}$. $\mathrm{x}$ 2 in. $x 1 / 8$ in. angle iron and bolted to the top of the steel cart on which the mini-DRIFT machine was mounted to keep from moving. The puller speed can be varied between 0.55 and 33 $\mathrm{m} /$ minute.

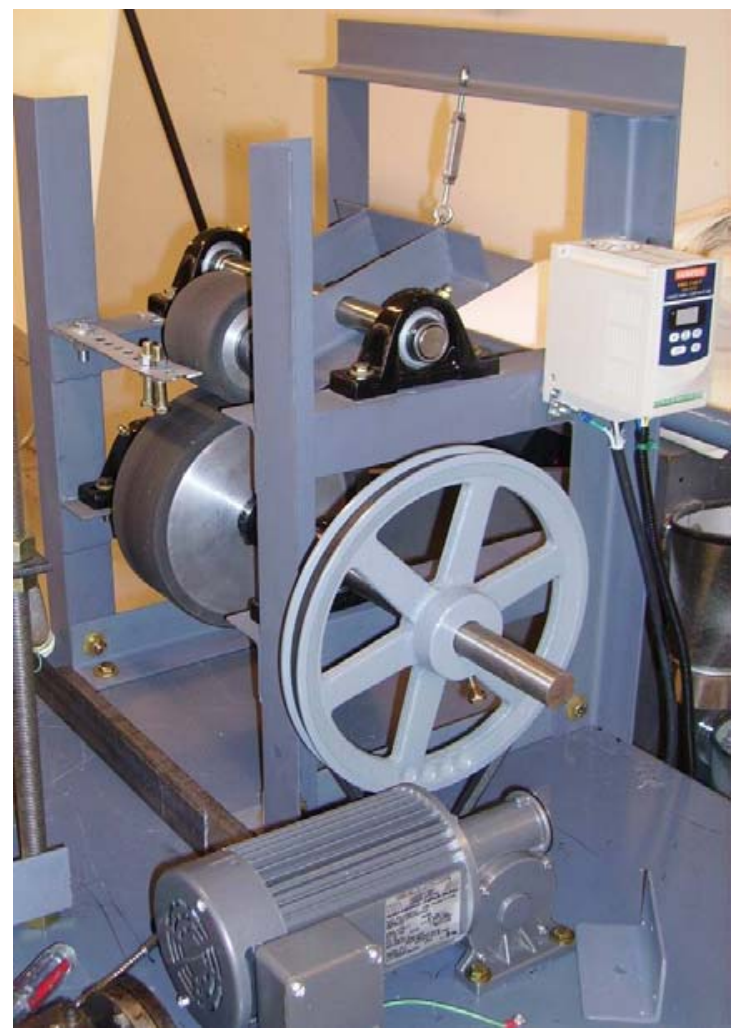

Figure 15. Completed puller system.

A brake system for the fiber feeding was also needed. The final brake design can accommodate fibers on any size spool. The final design involved attaching an adjustable magnetic brake to the end of a keyed shaft. The magnetic brake unit purchased was Precision Tork ${ }^{\mathrm{TM}}$ model MC5 capable of being adjusted from 0-25 in.-lb of torque. The actual force applied by the brake unit depends on the radius of the fiber spool. With the goal of great flexibility, the brake unit was modified to accept fibers regardless of their storage system. The system was retrofitted with drums similar to the puller unit and an adjustable upper arm. Fibers were routed to the drums through a system of guides. The guide configuration used depended on the dispensing system of the fibers and was left to the discretion of the researcher. The frame for the unit was also constructed from 2 in. $x 2$ in. $x 1 / 8$ in. angle iron and bolted to the lower shelf of one of the carts to conserve space and to minimize fiber exposure. Fibers were routed through the system through a series of guides. Figure 16 shows the final brake design. 


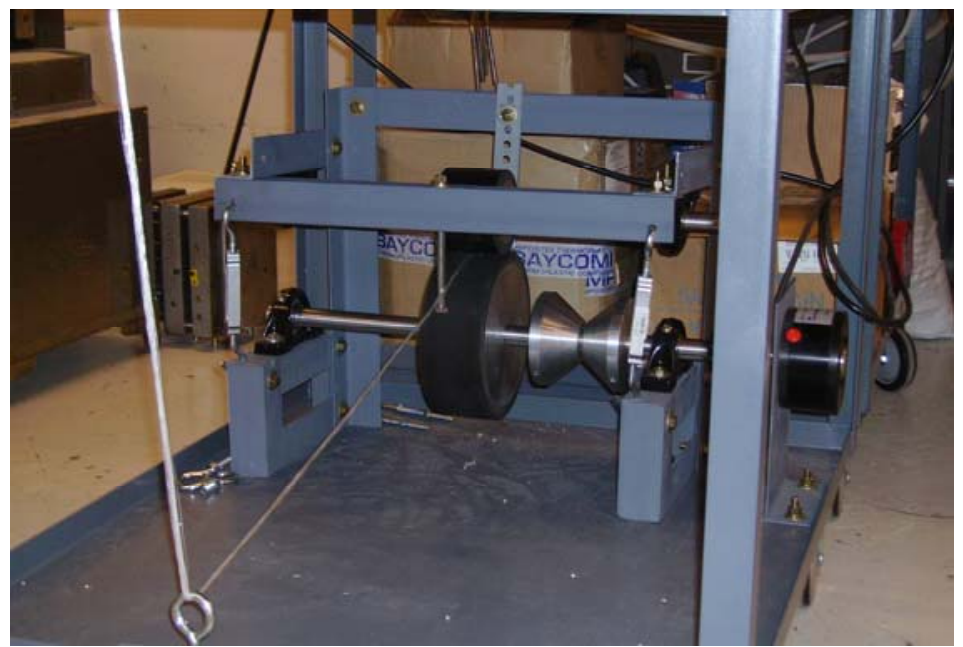

Figure 16. Final brake design.

The next portion of the system to be designed was the fiber heating section. This variable is one of the key to the DRIFT process. The final design consisted of a tube furnace that allowed the fibers to be heated as they passed through the furnace to the opening of the impregnation tool. A Lindberg Mini-Mite tube furnace was purchased for this task and can be seen in Figure 17. The furnace has a single heating zone with a maximum operating temperature of $1100{ }^{\circ} \mathrm{C}$ and a single set point digital controller. An 18 in. long by 1 in. outer diameter alumina process-tube was placed inside the furnace. The length of the tube purchased was chosen so that the tube could extend beyond the furnace and be butted up to the impregnation tool to insulate the fibers as they passed from the furnace to the impregnation tool. The fiber guide system for the machine ensured that the fibers do not touch the walls of the process tube.

The final portion of the mini-DRIFT machine to be designed was the chiller system. The chiller system chosen is shown in Figure 18. The chiller uses two stainless steel drums with water circulating internally acting as a coolant. Water is passed through the drums through swivel joints on the ends of either drum. The drums are supported by bearings bolted to adjustable platforms, allowing the configuration of the drums to be changed for routing purposes. The system was initially cooled using only tap water. The system could also utilize a re-circulating water cooler for greater system control, although that was not done here. Figure 19 shows the assembled system used for assessment of product quality. This system meets all the requirements specified earlier.

\section{Assessment of Product Quality}

The product quality of tapes manufactured by the mini-DRIFT machine described previously was accomplished by two primary methods, tensile testing of the tapes produced and microscopic analysis of the materials. In microscopic analysis, fiber dispersion was examined through both optical and scanning electron microscopic (SEM) techniques, while wetting was primarily examined by SEM. Composite samples were made with polypropylene as the polymer matrix. Both pitch and PAN carbon fibers were used as reinforcement. Tensile testing and 
microscopic examination of these two composites systems were then compared to each other. In addition, the effect of fiber preheat temperature was also examined.

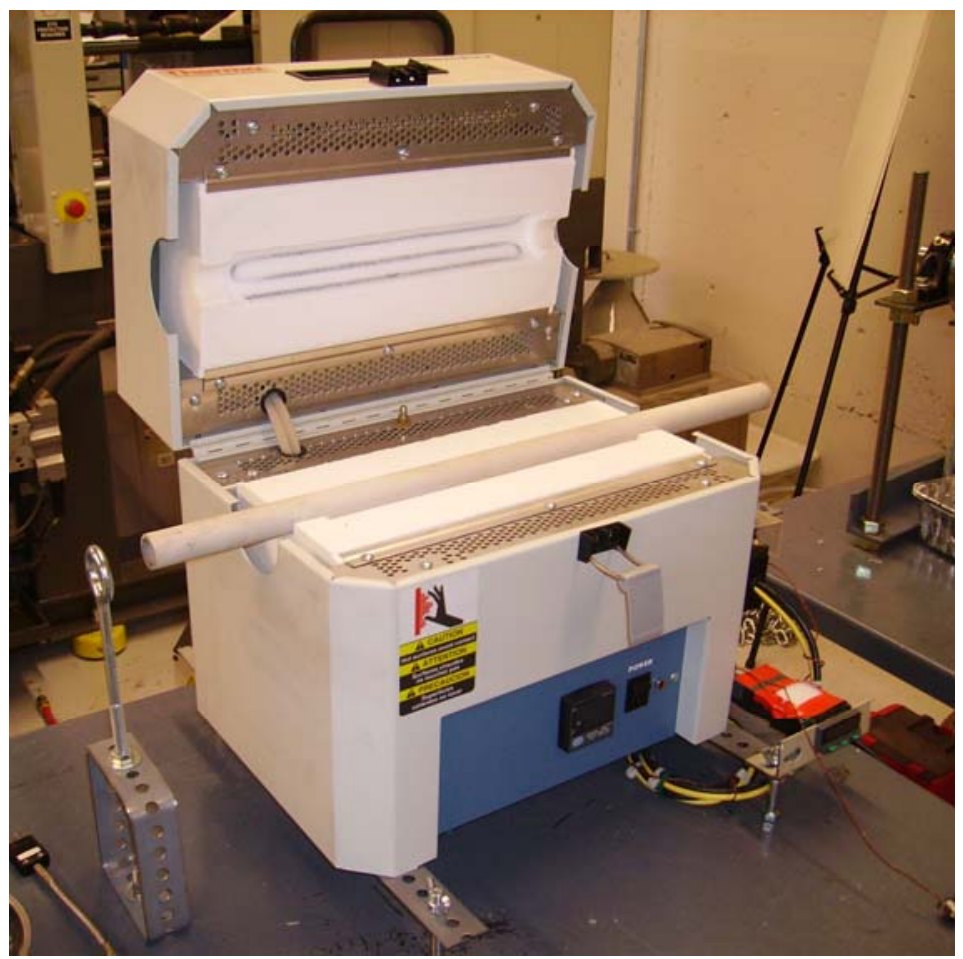

Figure 17. Tube furnace with its top open showing the process tube.

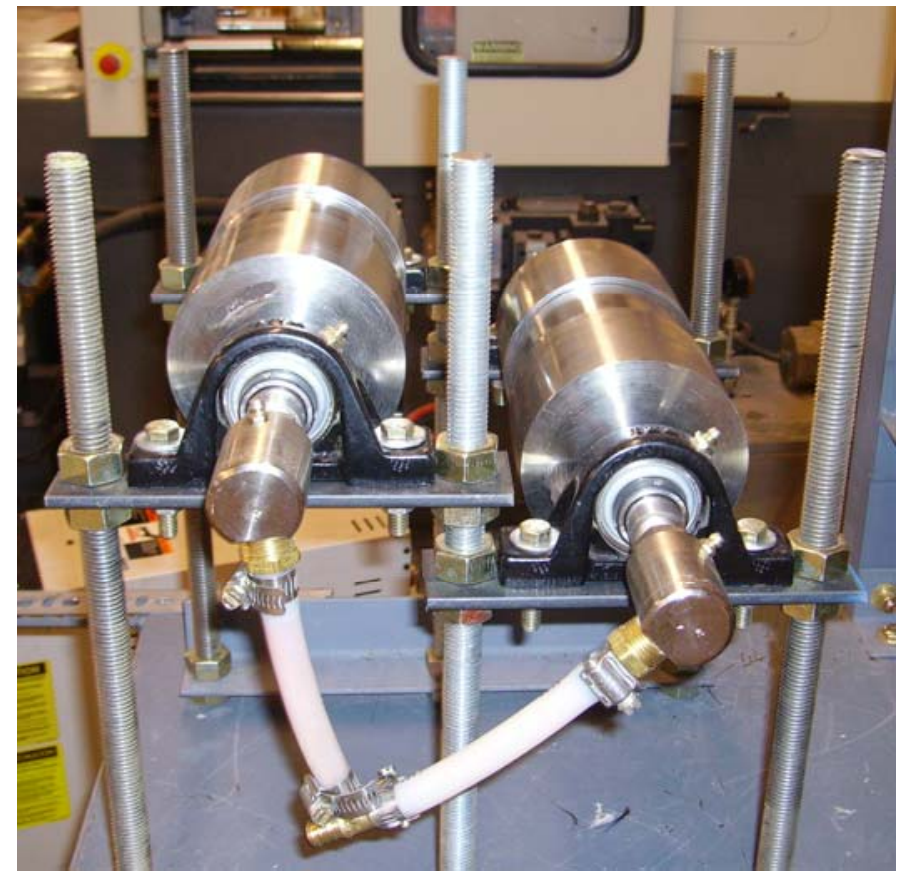

Figure 18. Chiller system. 


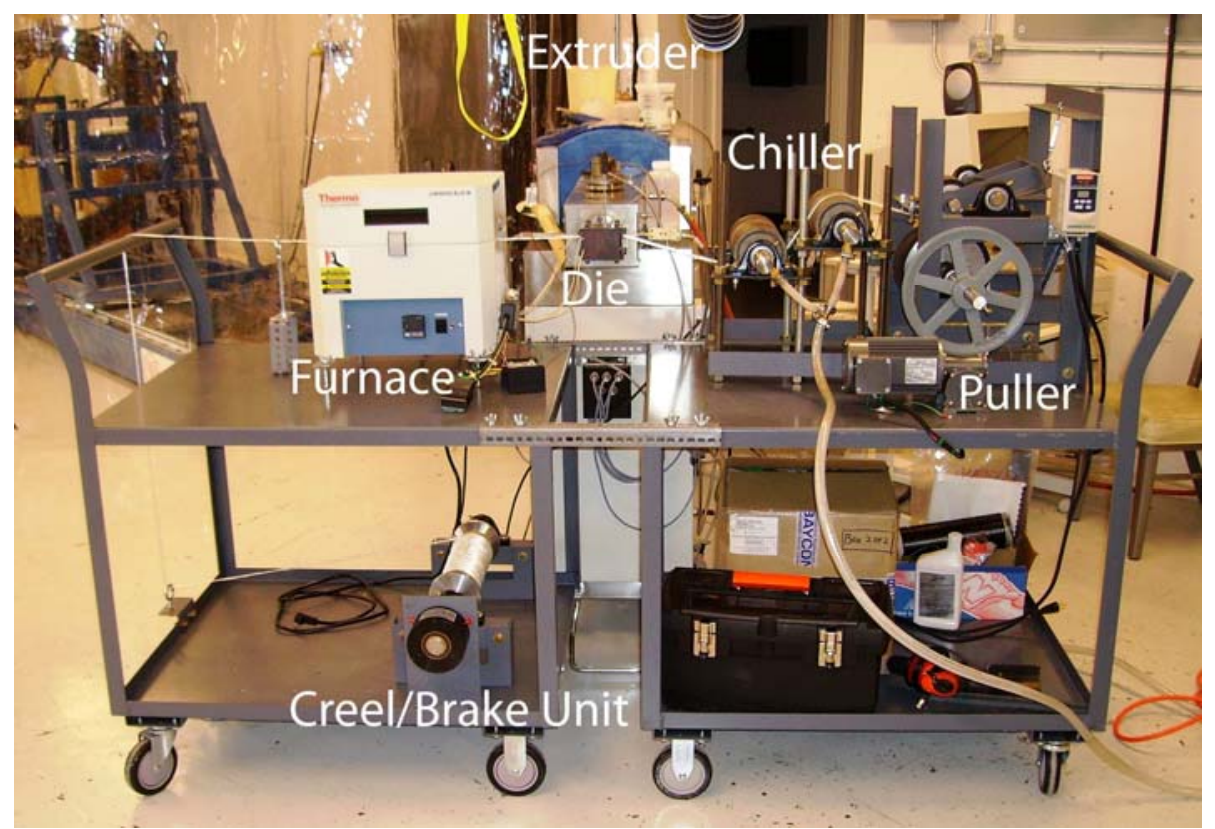

Figure 19. Completed miniature DRIFT system.

\section{Tensile Testing}

Tapes were manufactured using both PAN and pitch-based carbon fiber reinforcement in polypropylene matrix, and mechanical performance assessed by tensile testing. Tensile tests were conducted following the guidelines set forth in ASTM D 3039/ ASTM D 3039M with the exception that the samples produced did not meet dimensional tolerance requirements. As such, the measurement and calculation methods used came from the standard. Figure 20 shows a stress-strain curve resulting from tensile testing. From this data, the modulus of elasticity, the maximum tensile strength, the elongation at break and the modulus of resilience were determined as per ASTM D3039M. The stress-strain curve in Figure 8 shows that the composite is brittle, as little deviation from linearity is observed. At least five samples were tested for every fiber/matrix and processing temperature combination to help to understand the variability of the manufacturing process. The results are shown in Figures 21-24. In general, the PAN-fiber composites showed better properties, as expected. There does not to be a large difference in the properties of either composite system as the fiber pre-heat temperature increased. The mean behavior at room temperature is often slightly less than the properties found when the fibers are preheated, but this was within the $10-15 \%$ variation between samples. Complete description and results of all testing are given in Mr. R.D. McGlothlen's M.S. thesis.

The tensile strength was examined further by comparing the measured value to the value calculated from the rule of mixtures. At all fiber preheating temperatures and fiber types, the measured strength was $66-75 \%$ of the theoretical value. This decrease is likely due to damage to the fibers during processing. However, little of this decrease is due to preheating the fiber. 


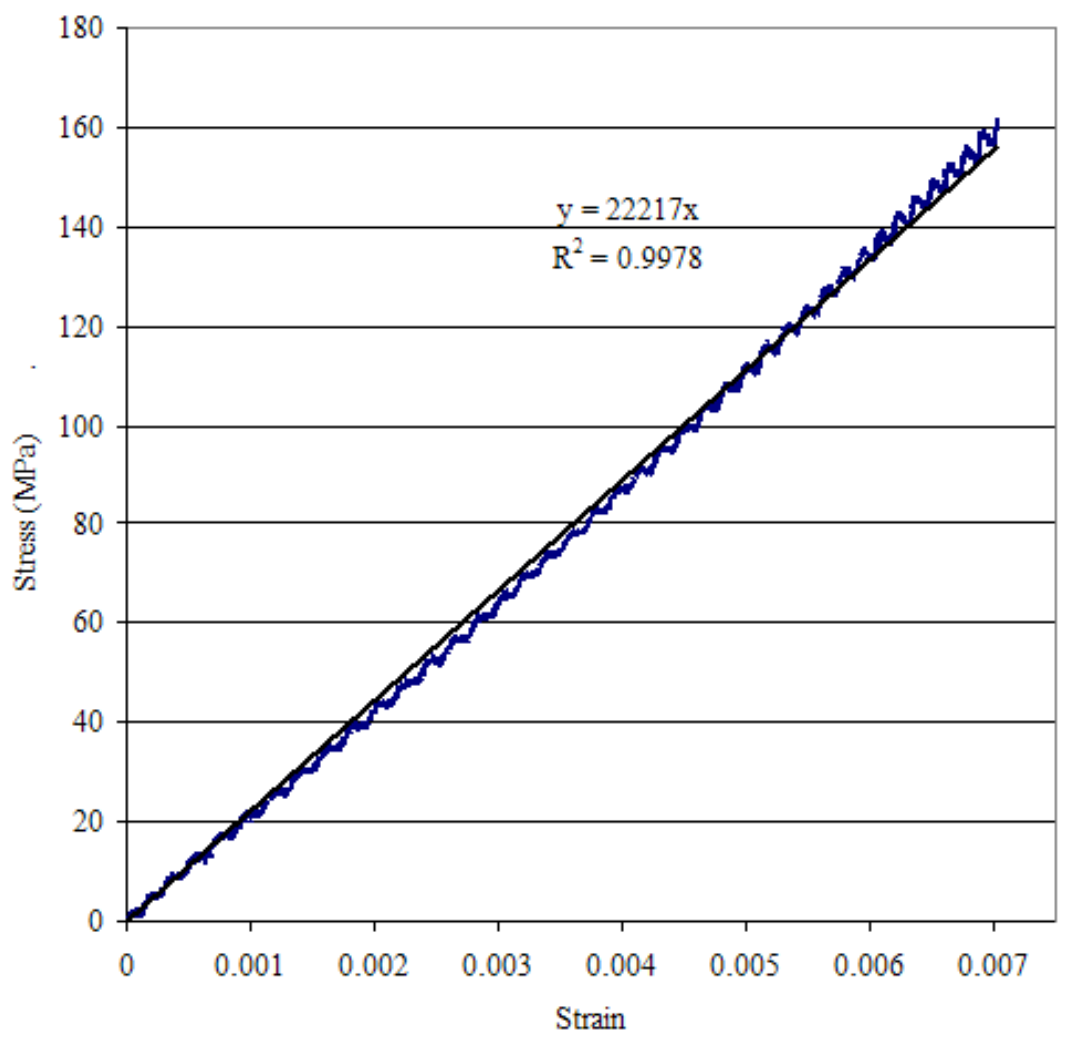

Figure 20. Example pitch $225^{\circ} \mathrm{C}$ sample stress-strain plot as a function of fiber pre-heat temperature.

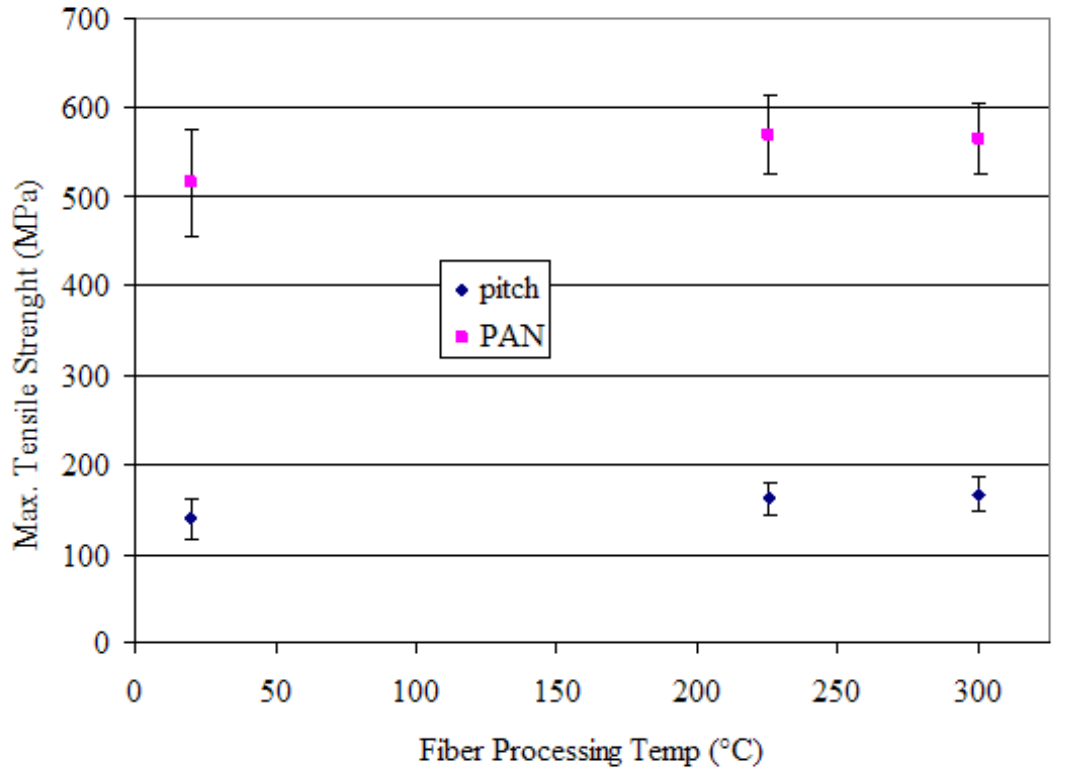

Figure 21. Maximum tensile strength for each sample set as a function of fiber pre-heat temperature. 


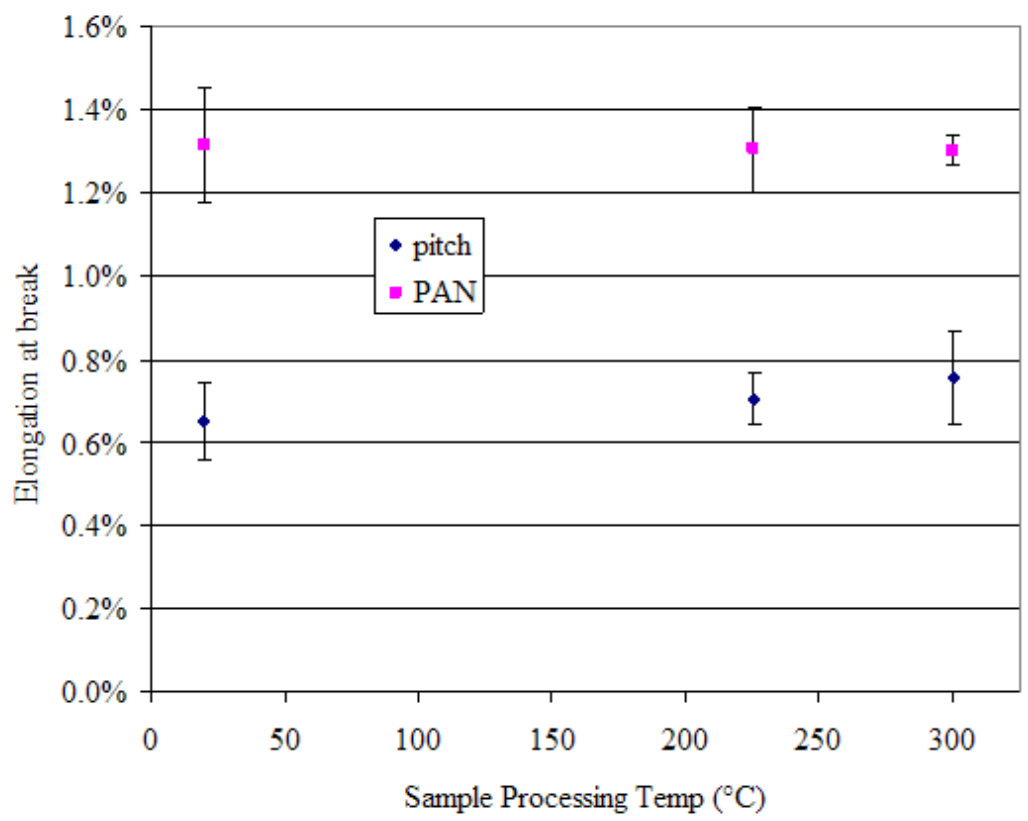

Figure 22. Elongation at break as a function of fiber pre-heat temperature.

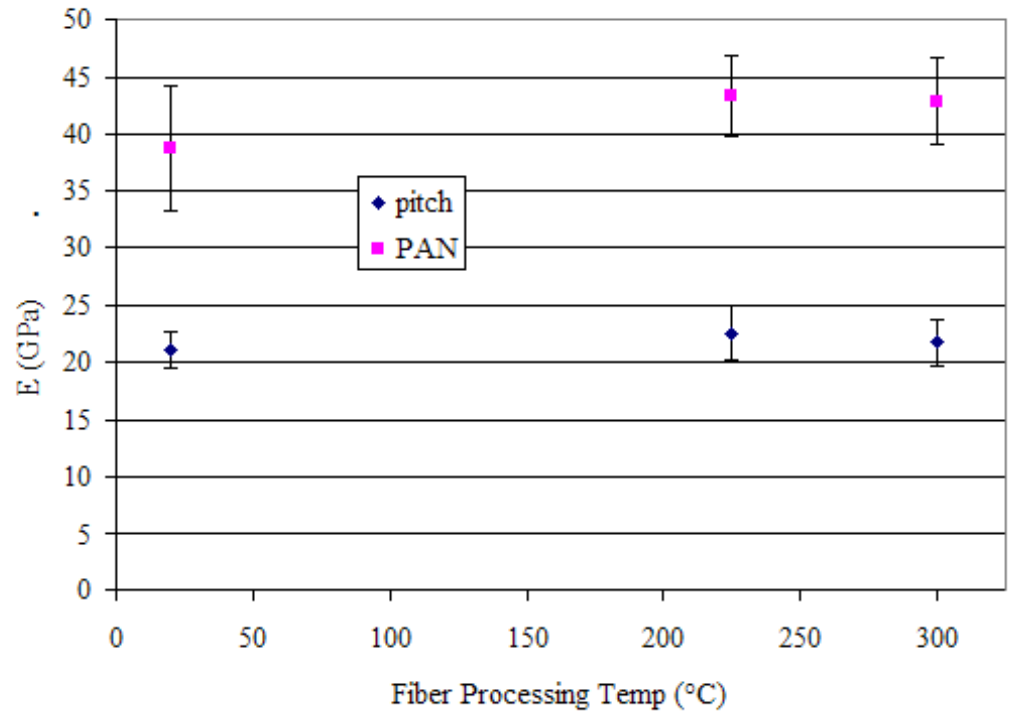

Figure 23. Elastic modulus as a function of fiber pre-heat temperature. 


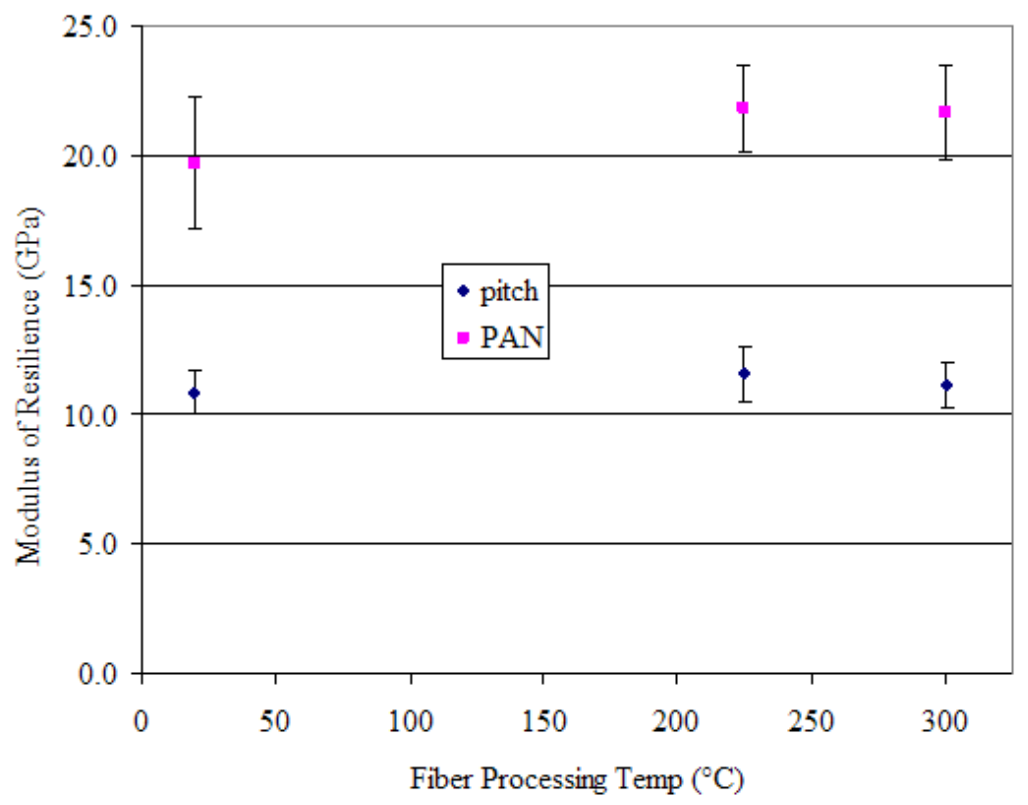

Figure 24. Modulus of resilience as a function of fiber pre-heat temperature.

\section{Optical Microscopy}

Next, tape samples were embedded in an epoxy matrix, sectioned, polished to $0.3 \mu \mathrm{m}$ with alumina polishing compound, then viewed with a VanGuard microscope having 4x, 10x, 40x, and 80x lenses using a Steindorff digital camera having 10x magnification yielding magnifications between 40x and 800x. The overall fiber dispersion of tapes of each type (pitch and PAN) and fiber pre-heating $\left(25,250,300^{\circ} \mathrm{C}\right)$ was determined by optical microscopy at $40 \mathrm{x}$. Full descriptions of all images are given Mr. McGlothlen's M.S. Thesis. Figure 25 shows a typical tape with pitch fibers, Figure 26 for PAN fibers. All tapes showed that the edges had more fibers than the center region, as can be seen in Figures 25 and 26. In addition, the center regions had large regions of nearly pure matrix. These pure matrix regions were usually above/below a row of fibers, and in some cases between concentrations of fiber. Higher magnifications were used to examine the wetting and dispersion more closely. Figures 27 (100x) and 28 (400x) show examples of the optical micrographs collected. In Figure 27, the pitch fibers are observed to be larger in diameter than the PAN fibers. Also, a few extremely large diameter pitch fibers can be seen, as can fibers that are similar to pies with a missing piece. In both composite systems, the fibers appear reasonably well wet by the polymer, although some of the pitch fiber composites show more voids in the polymer matrix. The PAN fiber composites were also examined at high magnification, 800x (Figure 29). The PAN fibers appear to be well dispersed and wet. In addition, the PAN fibers are observed to have a very consistent diameter.

The observations from these samples highlight the need for more investigation into the mechanisms involved in dispersing the fibers in the matrix in order to create a more uniform composite. 


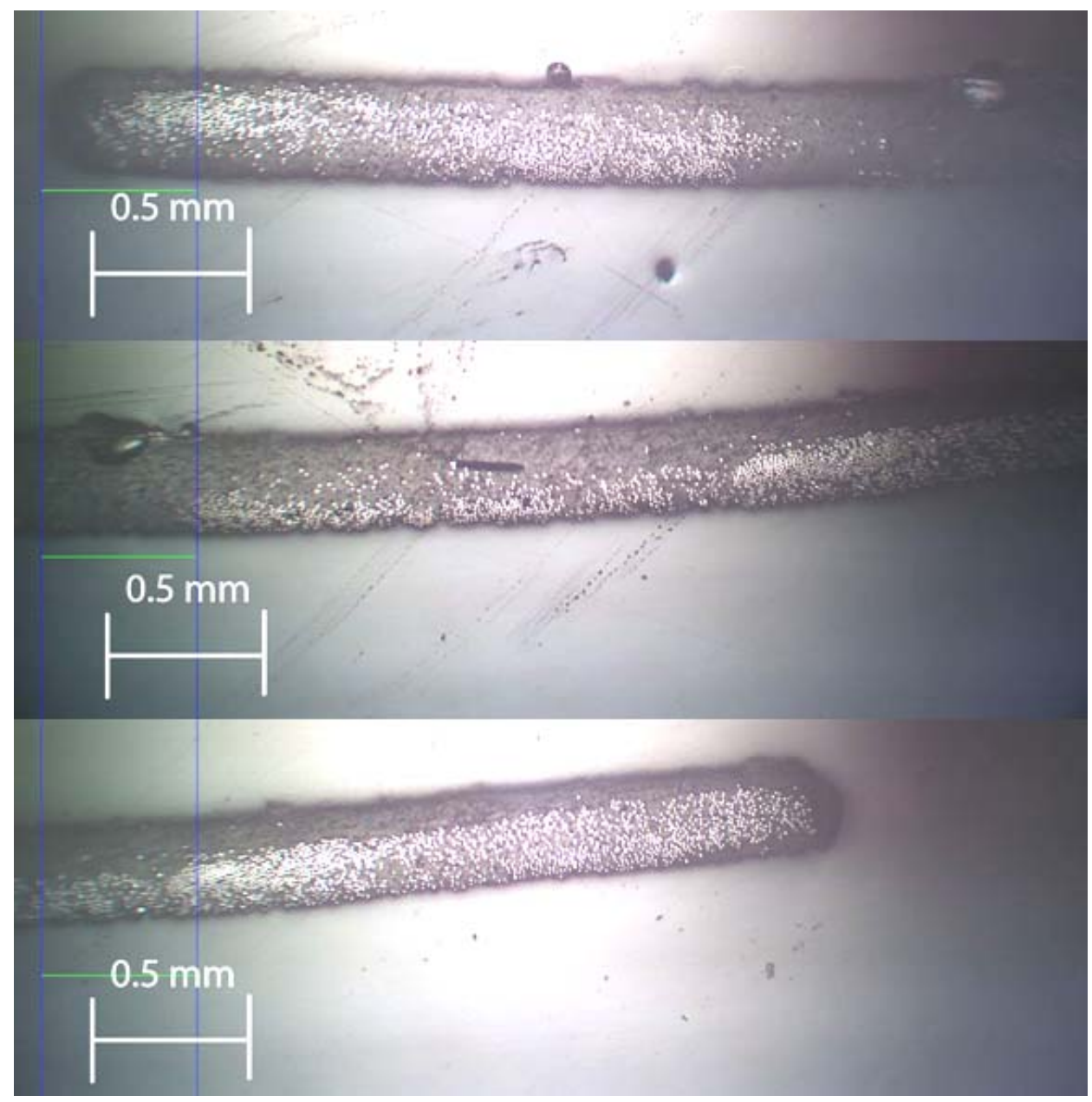

Figure 25. Images showing full width of room temperature preheat pitch sample (40x).

\section{Scanning Electron Microscopy}

Fractured tensile samples were viewed on the scanning electron microscope (SEM). The SEM used was a Carl Zeiss Supra 40VP field emission scanning electron microscope. Samples were gold coated to give images a greater depth of focus. All images were taken at $10 \mathrm{kV}$ excitation energy. SEM images were taken of the fractured surface of tested tensile samples. In many cases, the SEM images confirmed what was observed by optical microscopy. Full descriptions of all images are given Mr. McGlothlen's M.S. Thesis. From Figure 30 it can be noted that the room temperature preheat fibers are concentrated towards the top of the sample while the $225^{\circ} \mathrm{C}$ preheat fibers were more evenly distributed through the thickness. Fiber pullout is also shown by the holes in the matrices. A higher magnification image of an area showing a block of matrix with fibers is shown in Figure 31. The fibers appear to be well wet by the matrix.

By comparison PAN fiber composites exhibited much longer fiber pullout lengths as shown in Figure 32. Because of this, examining the regions between the fibers was more difficult. However, Figure 33 shows a close-up of one region exhibiting considerable matrix existing between the pulled-out fibers. 


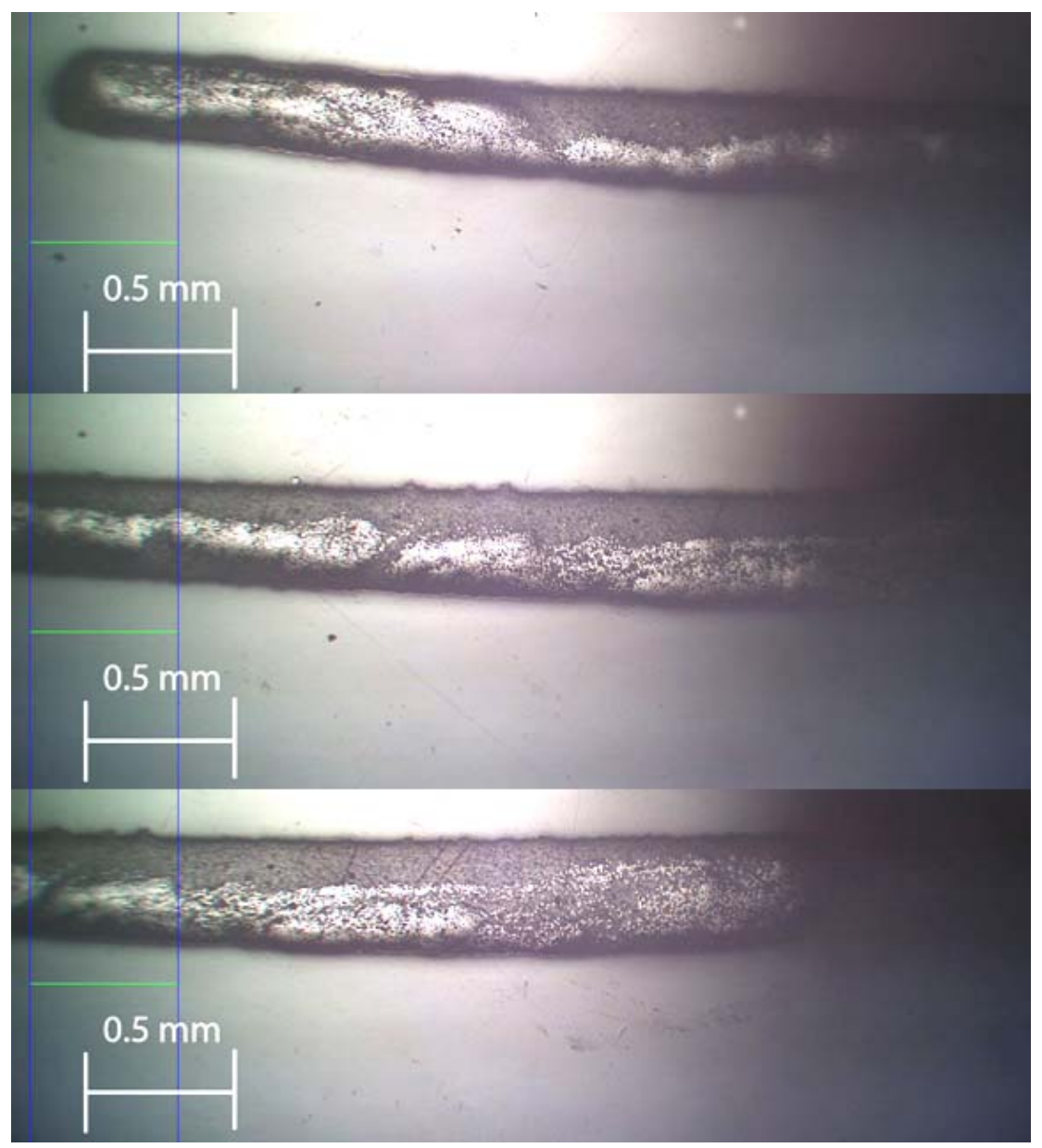

Figure 26. Images showing full width of room temperature preheat PAN sample (40x).

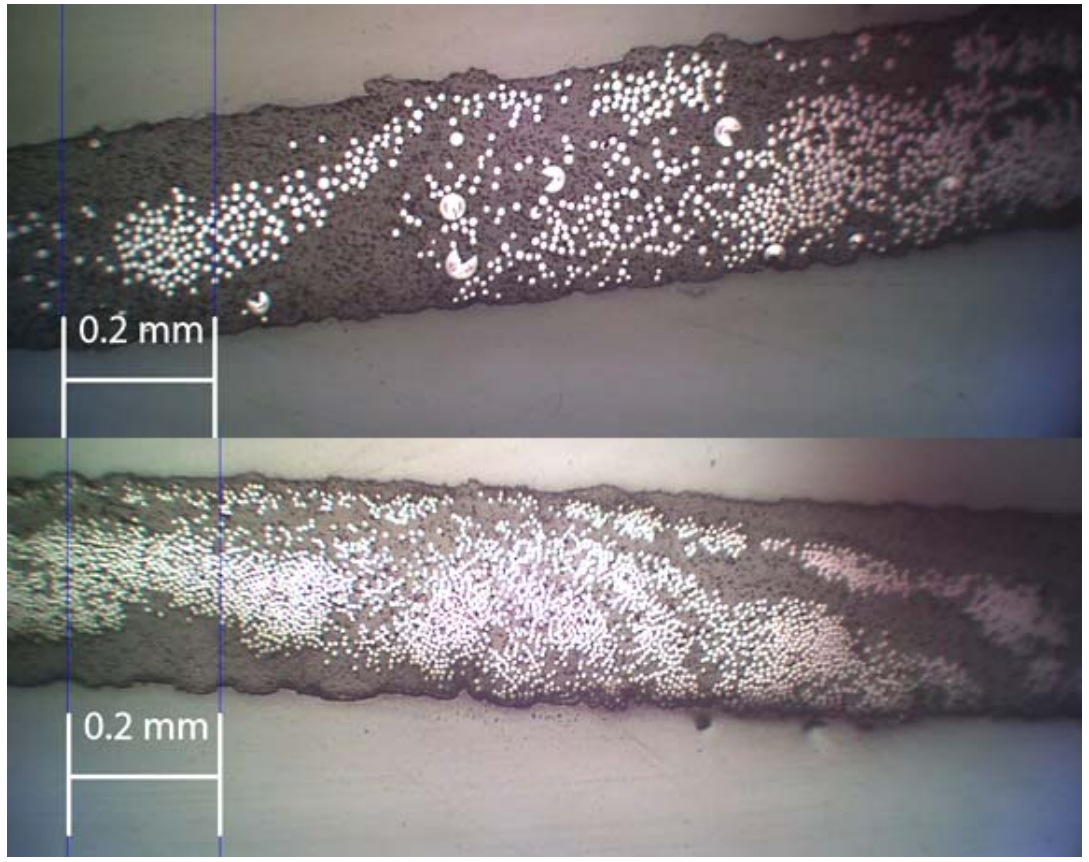

Figure 27. Comparison of pitch (top) and PAN (bottom) fiber composites at 100x. 


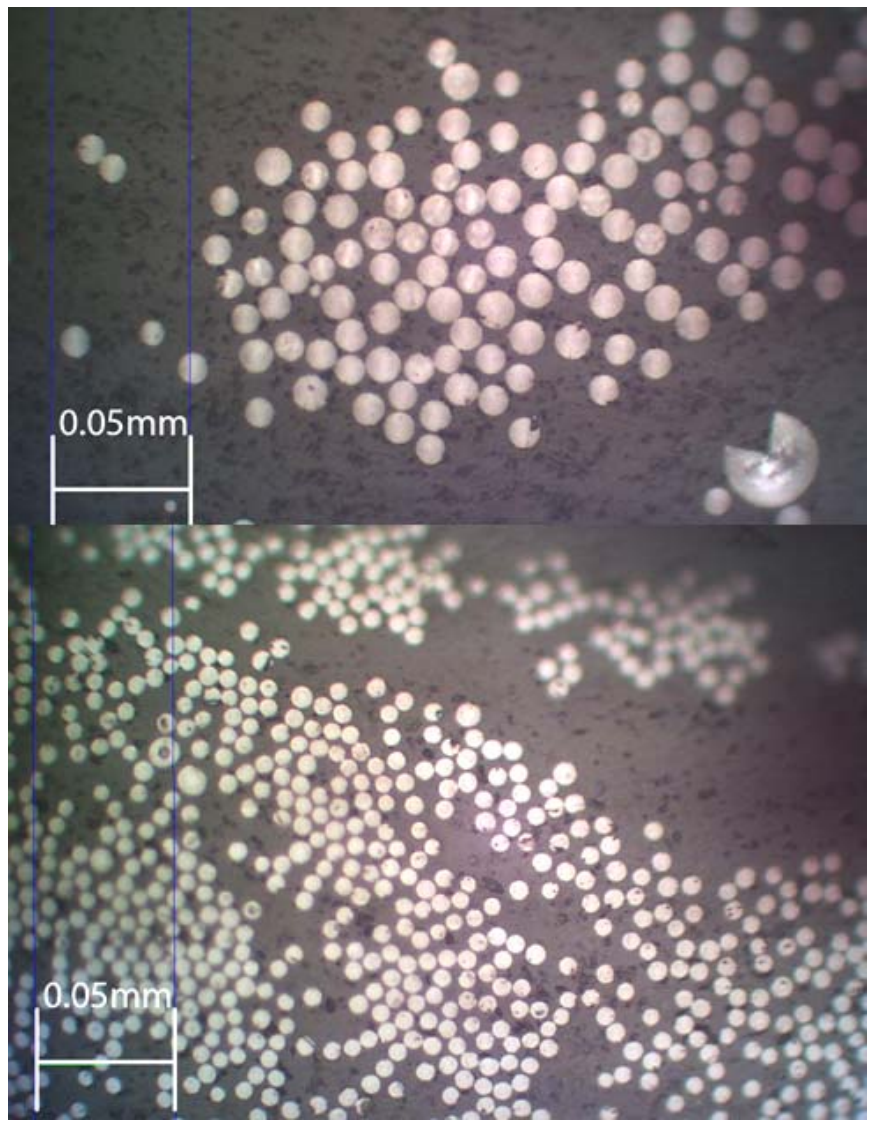

Figure 28. Comparison of pitch (top) and PAN (bottom) fiber composites at 400x.

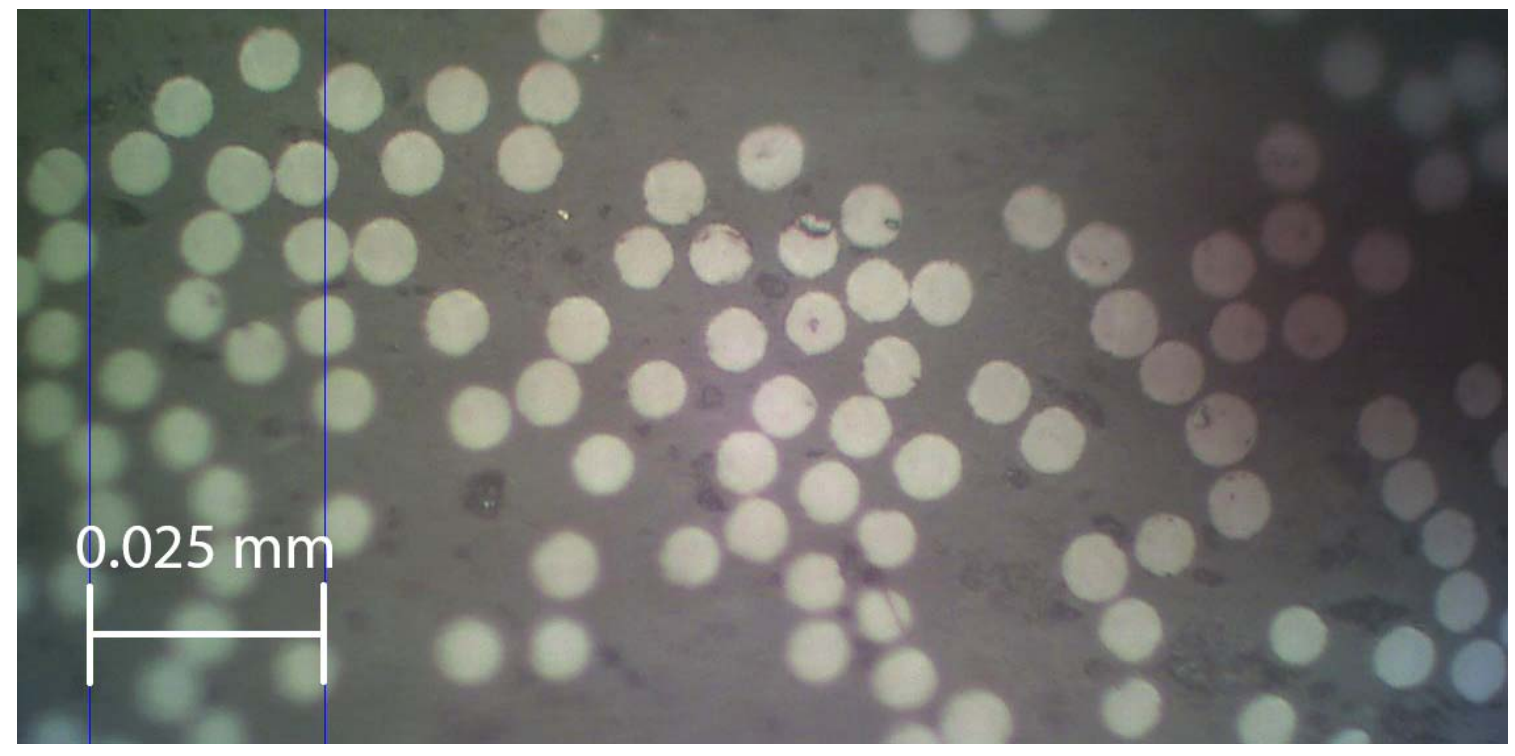

Figure 29. PAN fiber composite at $800 x$. 


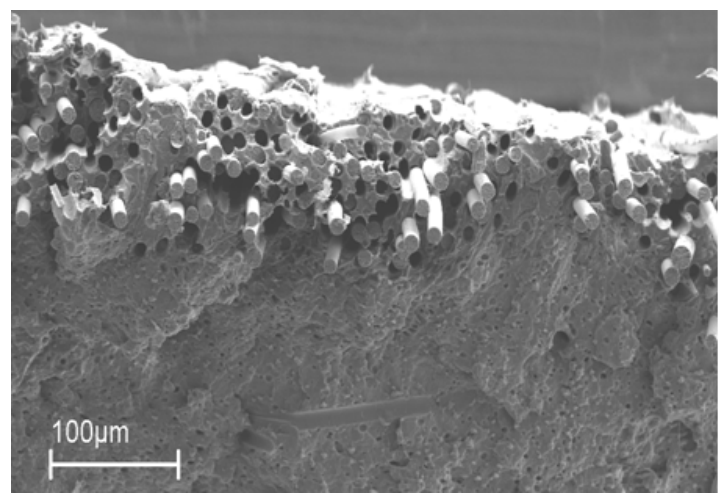

(a)

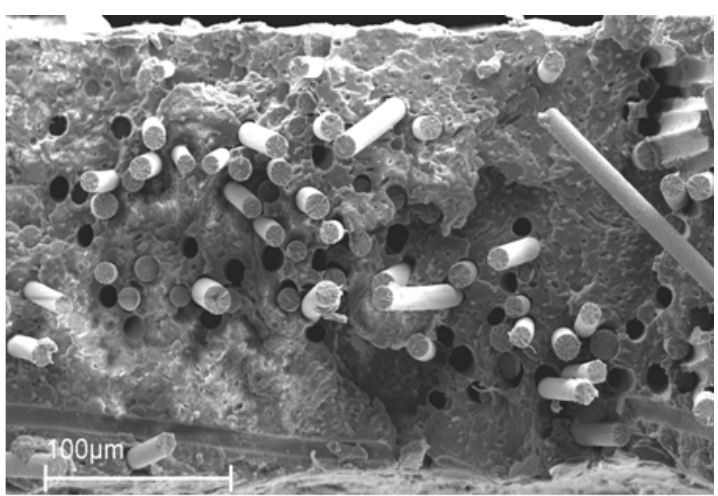

(b)

Figure 30. Fracture surface SEM micrographs of through thickness of pitch fiber composites with room temperature (a) and $225^{\circ} \mathrm{C}(\mathrm{b})$ preheat.

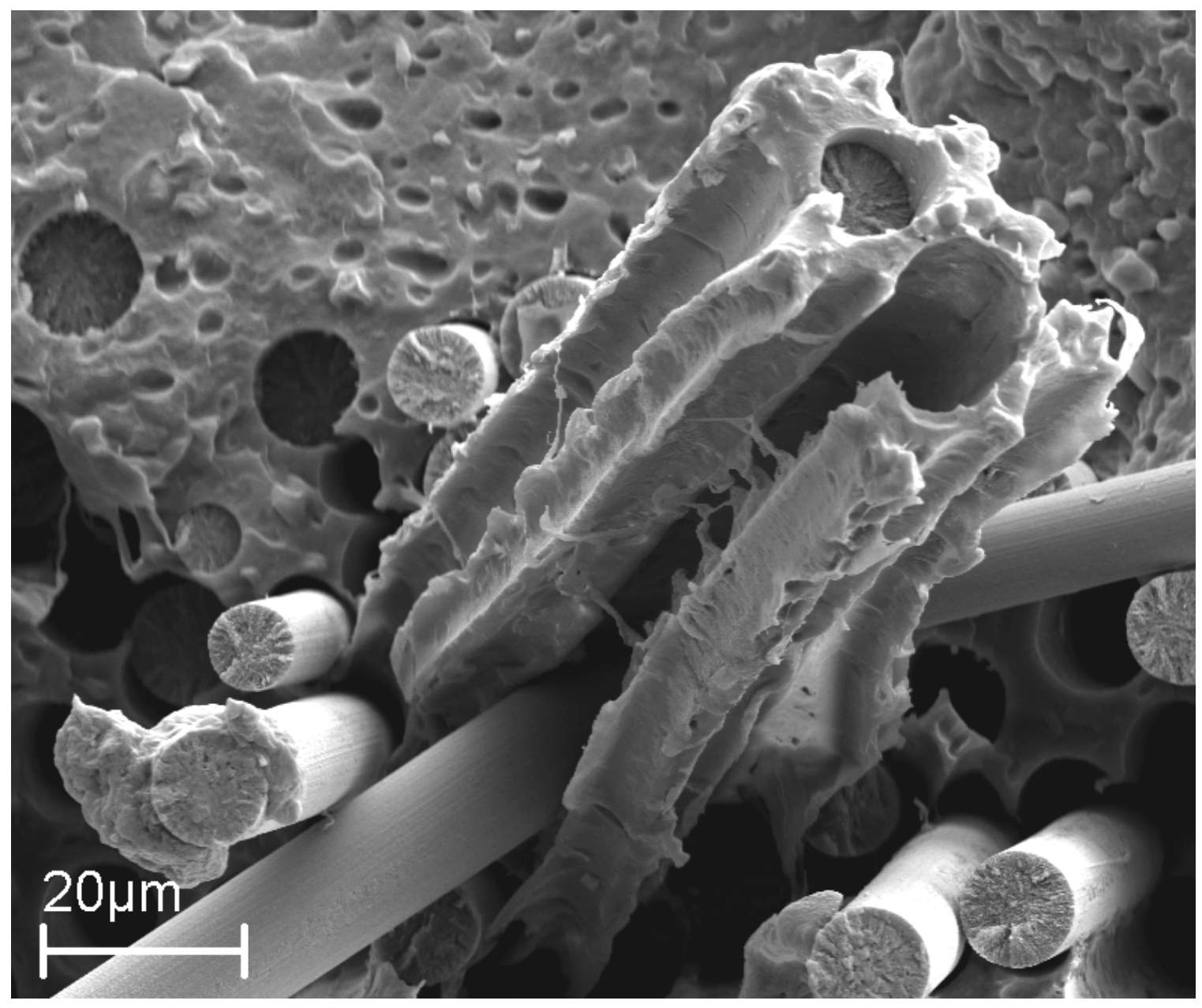

Figure 31. Close-up of fiber pullout on the fracture surface of a pitch composite. 

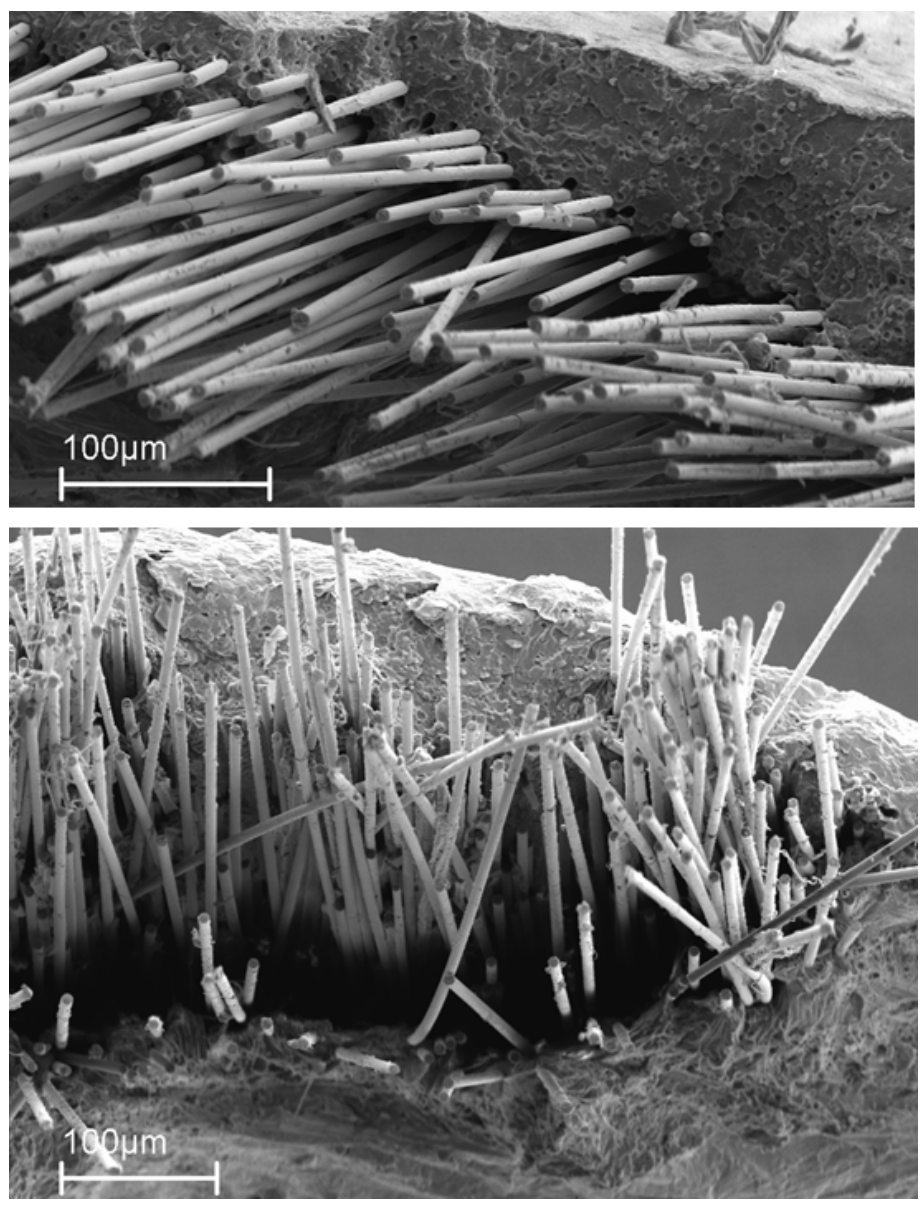

Figure 32. Fracture surface of PAN fiber composites with $225^{\circ} \mathrm{C}$ (top) and $300{ }^{\circ} \mathrm{C}$ (bottom) fiber preheat.

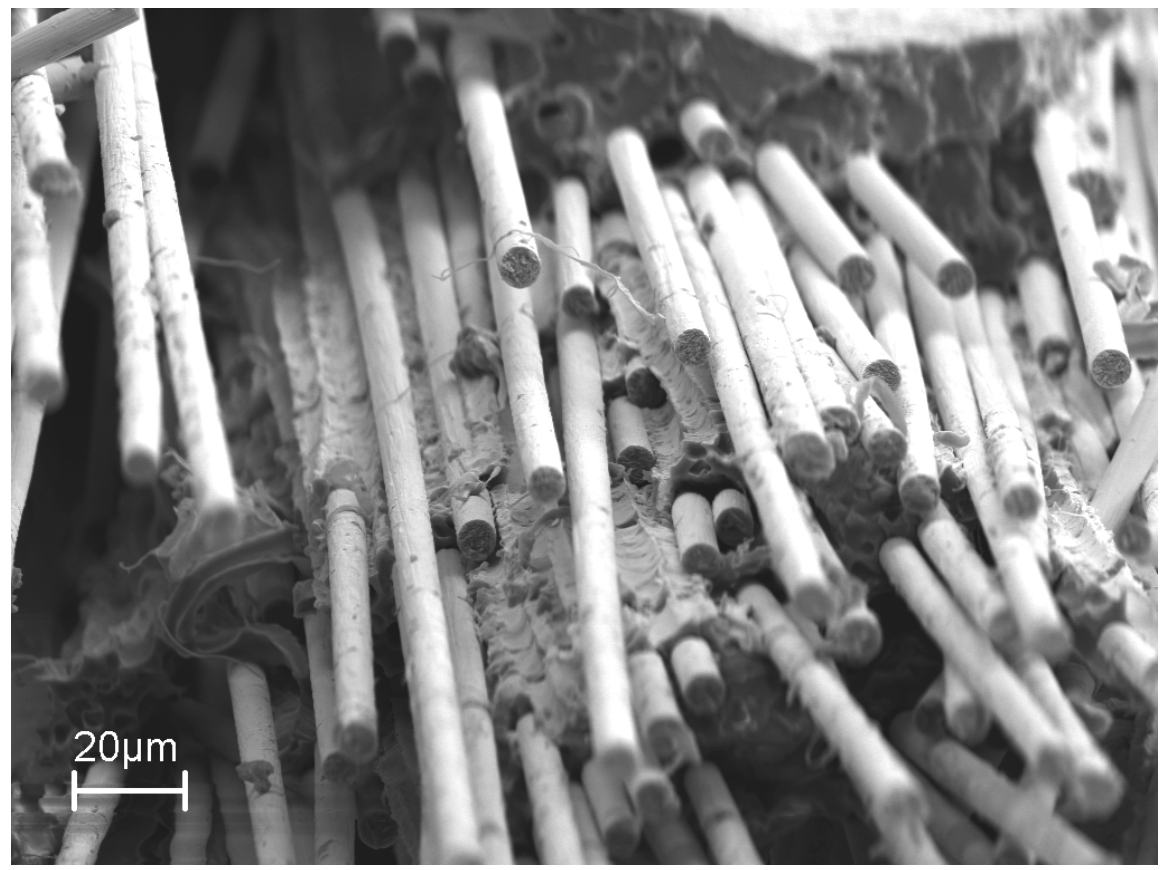

Figure 33. Close-up of fiber pullout on the fracture surface of a PAN composite. 


\section{PRESENTATIONS/PUBLICATIONS}

1. L. Nielsen, W. Cross, L. Kjerengtroen and J. Kellar, "Characterization of Transcrystalline Zones by Atomic Force Microscopy," 2006 South Dakota EPSCoR Conference, Rapid City, SD September 2006.

2. T. A. Engstrom, G. Janchivdorj, W. M. Cross, L. Kjerengtroen, R. Norris, and J. J. Kellar, "Thermoplastic Matrix Composite Analysis using Resistively Heated Single Carbon Fibers," Gordon Research Conference---Composites, Ventura CA, January 2007.

3. L. Nielsen, W. Cross, R. McGlothlen, J. Kellar and L. Kjerengtroen, "Transcrystallinity Effects in Polypropylene Matrix Composites" 2006 South Dakota EPSCoR Conference, Rapid City, SD September 2006.

4. Bickett, S. J., "Investigation Of Transcrystallinity in Fiber Reinforced Thermoplastic Composites", Master of Science Thesis, South Dakota School of Mines and Technology, 2006.

5. Robinson, L., Cross, W.M., Kjerengtroen, L. and Kellar, J., "Thermoplastic Melting and Wetting Behavior on Carbon Fibers", Joint ND/SD EPSCoR Conference, Sept. 2007, Fargo, ND.

6. McGlothlen, R. G., "Design and Testing of a Compact DRIFT Machine for Manufacturing of Continuous Fiber Thermoplastic Composites", Master of Science Thesis, South Dakota School of Mines and Technology, 2008.

7. M. Alghamdi, R.D. McGlothlen, J.J. Kellar, W.M Cross and L. Kjerengtroen, "Design and Testing of a Compact Drift Machine for Manufacturing of Continuous Fiber Thermoplastic Composites," accepted for presentation and publication, SAMP 2009, Baltimore, MD.

\section{ACRONYMS}

ACC - Automotive composites consortium

AFM - Atomic force microscopy

ASTM - American Society for Testing of Materials

DOE - Department of Energy

DRIFT - Direct reinforcement fabrication technology

MSS - Mean shear strength

ORNL - Oak Ridge National Laboratories

PAN - Polyacrylonitrile carbon fibers

PMC - Polymer matrix composite

PP - Polypropylene

P4 - Programmable powered preform process

$\mathrm{TC}$ - Transcrystalline region

SDSM\&T - South Dakota School of Mines and Technology

SRI - Southern Research Institute

TC - Transcrystalline region

$\mathrm{UAB}$ - University of Alabama-Birmingham 


\section{PERSONNEL WHO CONTRIBUTED TO THIS PROJECT}

Dr. Jon J. Kellar (Professor)

Dr. William M. Cross (Associate Professor)

Dr. Lidvin Kjerengtroen (Professor)

Ms. L. Robinson (undergraduate student)

Ms. L.D. Nielsen (undergraduate student)

Mr. T.A. Engstrom (undergraduate student)

Mr. S.J. Bickett (graduate student)

Mr. R.D. McGlothlen (graduate student)

\section{FUNDING ENABLED BY THIS RESEARCH}

1. J. Kellar, W. Cross and L. Kjerengtroen, "Interphase Property Testing," Automotive Composites Consortium, \$21,500, 6/06-5/07. 